University of Louisville

ThinkIR: The University of Louisville's Institutional Repository

Electronic Theses and Dissertations

$5-2017$

\title{
Prenatal depression screening among a diverse healthy start population.
}

\author{
Evangeline Pierce \\ University of Louisville
}

Follow this and additional works at: https://ir.library.louisville.edu/etd

Part of the Epidemiology Commons

\section{Recommended Citation}

Pierce, Evangeline, "Prenatal depression screening among a diverse healthy start population." (2017). Electronic Theses and Dissertations. Paper 2671.

https://doi.org/10.18297/etd/2671

This Master's Thesis is brought to you for free and open access by ThinkIR: The University of Louisville's Institutional Repository. It has been accepted for inclusion in Electronic Theses and Dissertations by an authorized administrator of ThinkIR: The University of Louisville's Institutional Repository. This title appears here courtesy of the author, who has retained all other copyrights. For more information, please contact thinkir@louisville.edu. 


\title{
PRENATAL DEPRESSION SCREENING
}

\section{AMONG A DIVERSE HEALTHY START POPULATION}

\section{By}

\author{
Evangeline Pierce \\ B.S., Western Kentucky University 2010
}

\begin{abstract}
A Thesis Submitted to the Faculty of the
School of Public Health and Information Sciences of the University of Louisville in Partial Fulfillment of the Requirements for the Degree of

Master of Science in Epidemiology

Department of Epidemiology

University of Louisville

Louisville, Kentucky
\end{abstract}

May 2017 

PRENATAL DEPRESSION SCREENING

AMONG A DIVERSE HEALTHY START POPULATION

\title{
By
}

\author{
Evangeline Pierce
}

B.S., Western Kentucky University 2010

A Thesis Approved on

April 11, 2017

by the following Thesis Committee:

Anne Wallis, Ph.D. - Thesis Director

Richard Baumgartner, Ph.D

Scott LaJoie, Ph.D 


\section{ACKNOWLEDGEMENTS}

I would like to thank Dr. Anne Wallis for her knowledge and support throughout this process. I would also like to thank the other committee members, Dr. Richard Baumgartner and Dr. Scott LaJoie, for their comments and assistance along this journey. I am thankful to Darby Taylor and Healthy Start, Des Moines, lowa for the chance to work with their data. To my family and friends, thank you for supporting me in my life choices and always encouraging to be my very best. 


\section{ABSTRACT \\ PRENATAL DEPRESSION SCREENING \\ AMONG A DIVERSE HEALTHY START POPULATION \\ Evangeline Pierce}

April 11, 2017

Prenatal depression has been associated with adverse outcomes for both pregnant women and infants. Data was studied from Healthy Start $(n=1093)$. Healthy Start participants were screened for depression using the Edinburgh Postnatal Depression Scale (EPDS) during pregnancy. Data reported included birthweight, gestational length, ethnicity, and sociodemographic variables. No statistically significant association was found between a positive EPDS screen and birthweight-low/normal (OR 1.02 [95\% Cl 0.53, 1.70]), birthweight-abnormal (OR $1.02[95 \% \mathrm{Cl} 0.53,1.70]$, or gestation-preterm/term (OR $1.29[95 \% \mathrm{Cl} 0.68$, 2.45]). An association was observed between a positive screen and race, ethnicity by region of origin, immigrant status, English as a primary language, language by region of origin, pregnancy intention, smoking status, and alcohol consumption. Ethnicity and related variables may have associations with a positive EPDS screen, but this should be analyzed in a larger population. 


\section{TABLE OF CONTENTS}

PAGE

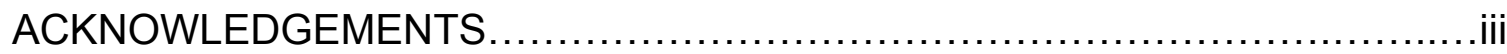

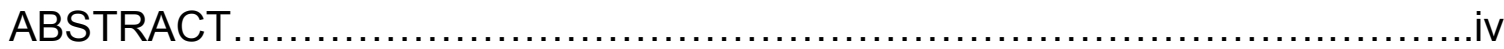

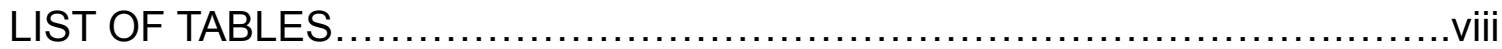

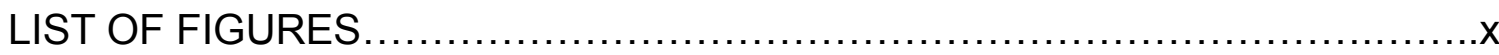

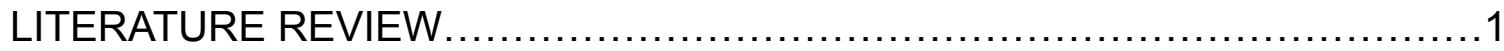

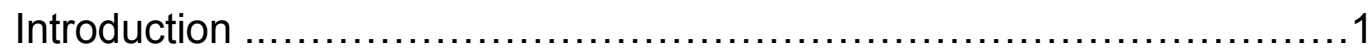

Depression in Pregnancy ................................................

Effects of Depression on Pregnancy .....................................

Association Between Prenatal Depression and Low Birth Weight...........3

No Association Between Prenatal Depression and Low Birth Weight......5

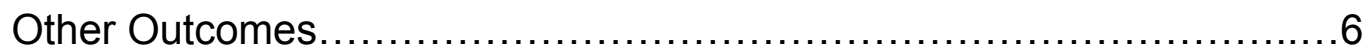

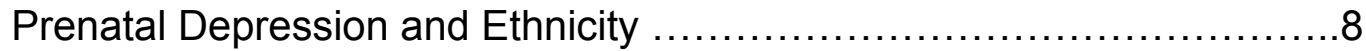

Prenatal Depression in Refugee Populations............................10

Edinburgh Postnatal Depression Scale (EPDS) ......................10

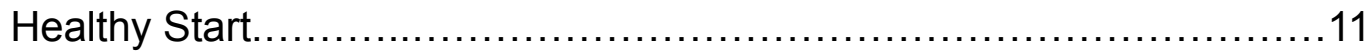

Conclusions................................................................

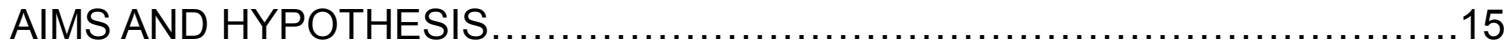


PAGE

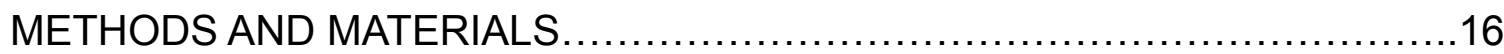

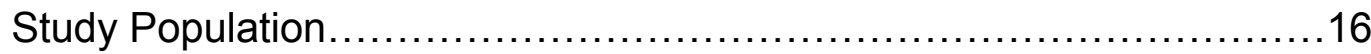

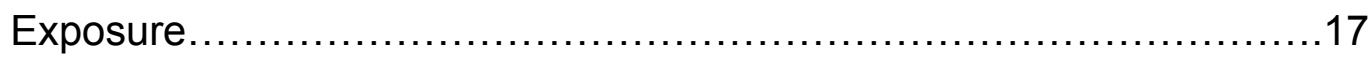

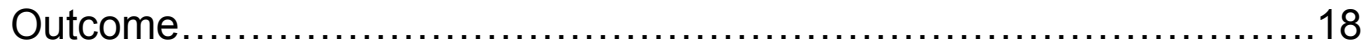

Other Variables..................................................................

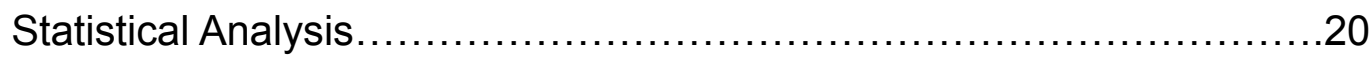

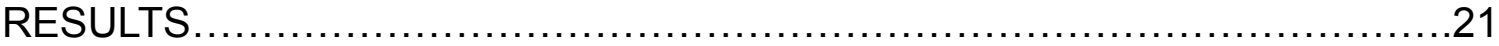

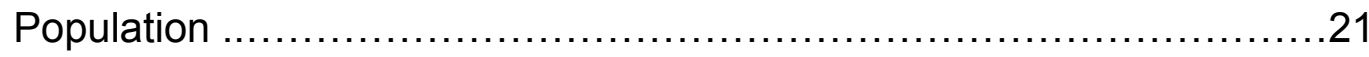

Assessment of the relationship between Birthweight and a Positive

Screen for Prenatal Depression .................................30

Assessment of the relationship between Gestational Age and a Positive

Screen for Prenatal Depression................................... 35

Assessment of the Relationship between a Positive Screen for Prenatal

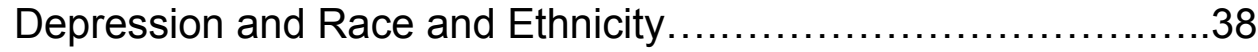

Assessment of the Relationship between a Positive Screen for Prenatal

Depression and Other Variables...................................39

Assessment of the Relationship between a Positive Screen for Prenatal

Depression and Ethnicity by Global Region. 


\section{TABLE OF CONTENTS, CONTINUED}

PAGE

Assessment of the Relationship between a Positive Screen for Prenatal

Depression and Language by Global Region 41

Assessment of the Relationship between a Positive Screen for Prenatal

Depression in Pregnancy and a Positive Screen for Prenatal

Depression at Program Intake...................................42

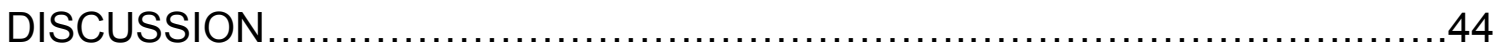

Discussion of Results................................................... 44

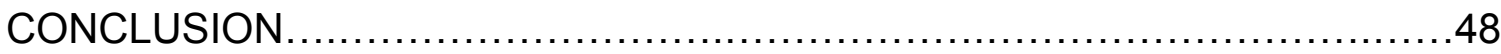

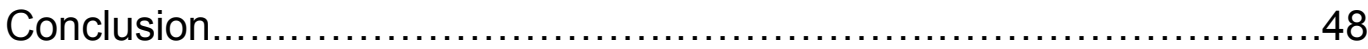

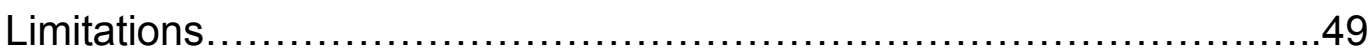

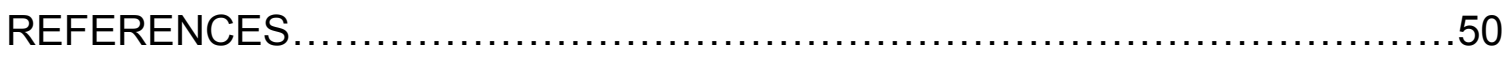

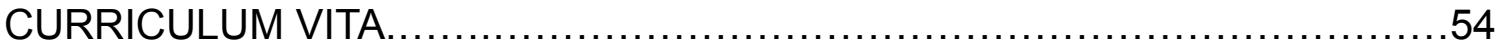




\section{LIST OF TABLES}

TABLE

PAGE

1. Association Between Prenatal Depression and Low Birth

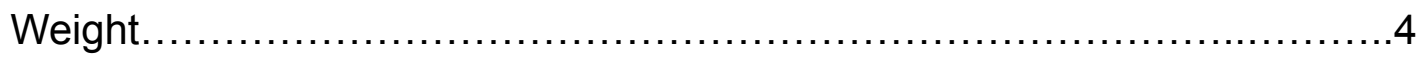

2. No Association Between Prenatal Depression and Low Birth

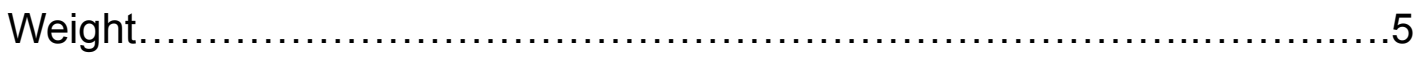

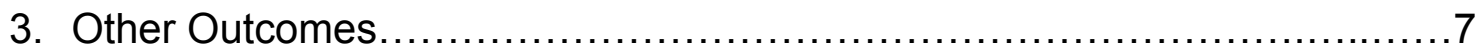

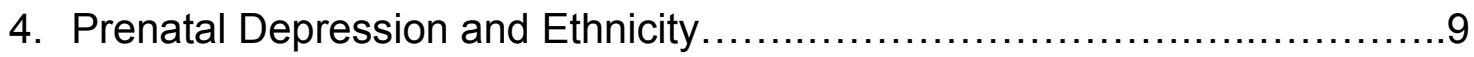

5. Descriptives for the Study Population.....................................28

6. Analysis: Birthweight and a Positive EPDS Screen...........................34

7. Breslow Day Tests: Birthweight and a Positive EPDS

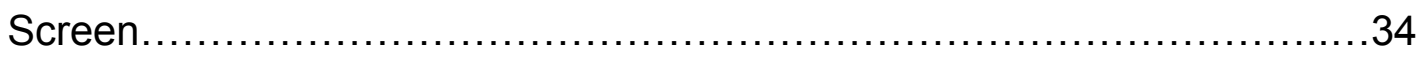

8. Further Logistical Analysis: Birthweight and a Positive EPDS

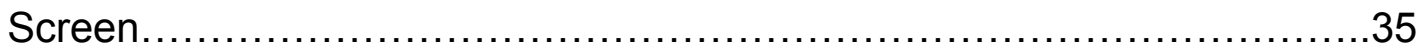

9. Analysis: Gestation Age and a Positive EPDS Screen.......................37

10. Breslow Day Tests: Gestation Age and a Positive EPDS

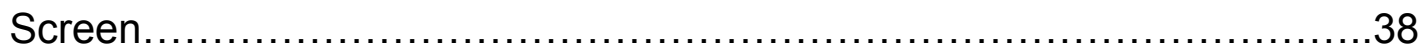

11. Further Logistical Analysis: Gestation Age and a Positive EPDS

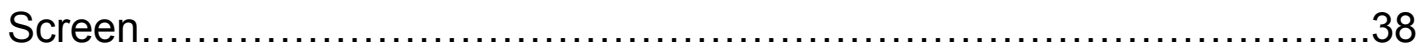




\section{LIST OF TABLES, CONTINUED}

TABLE

PAGE

12. Assessment of Variables and Screening Positive on EPDS

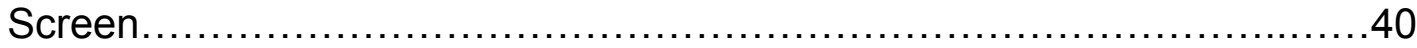

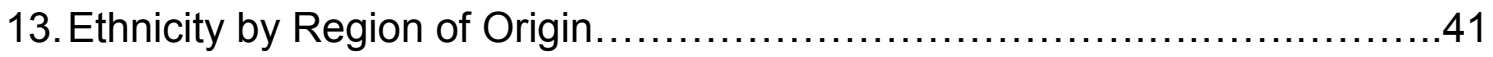

14. Language by Region of Origin ..........................................42 


\section{LIST OF FIGURES}

FIGURE

PAGE

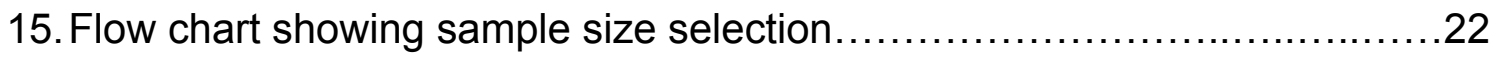

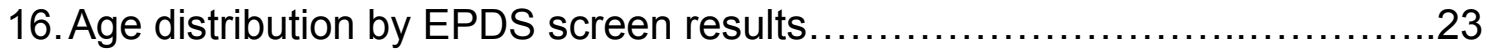

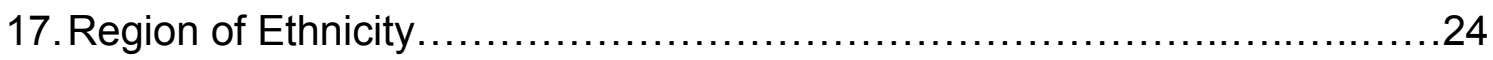

18. Country of Primary Language Spoken................................ 25

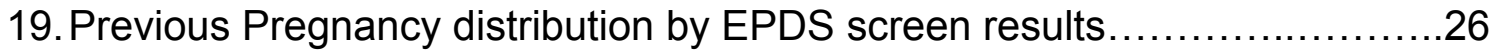

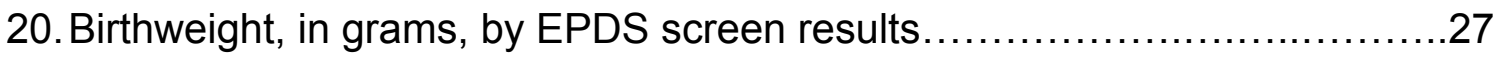

21. Gestational Age, in weeks, by EPDS screen results......................28

22. Birthweight divided into Low and Normal, by EPDS screen

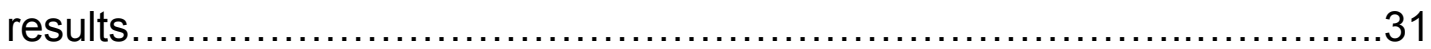

23. Birthweight divided into Abnormal and Normal, by EPDS screen

results

24. Gestational Age divided into Pre-Term and Full-Term, by EPDS screen

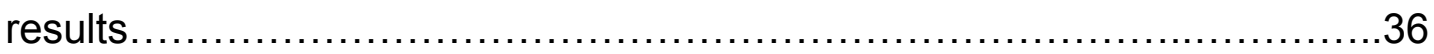

25. Flow chart showing change of EPDS score from program intake to pregnancy. 


\section{LITERATURE REVIEW}

\subsection{Introduction}

Depression affects many of the world's population which includes pregnant women. A review of the literature shows that some studies have found an association between prenatal depression and low birth weight (1-4). Other studies have discovered associations between prenatal depression and other negative birth outcomes (5-7). However many studies researching depression and pregnancy do not reach a consensus on associated birth outcomes (8-11). There are also other variables that play a role in prenatal depression.

\subsection{Depression in Pregnancy}

According to the 5th edition of the Diagnostic and Statistical Manual of Mental Disorders (DSM V) depression can be seen in a variety of symptoms: a depressed mood, changes in sleep, appetite, activity, feelings of guilt or worthlessness, ideations of death and suicide, loss of energy and fatigue, among many others (12). The current theories concerning the overall pathophysiology of depression include psychosocial stress, stress hormones, neurotransmitters, and 
circadian rhythms. There is not a unified hypothesis of depression, meaning that depression can be due to a variety of causes and exhibits itself in many ways there is no single path to depression (13). It is postulated that women have greater physiological response to stress than men do (13). This one thought that could potentially contribute to the difference seen in depression rates of men and women (13). Depression affects $9.3 \%$ of the women in the United States aged 18-39 years old while it only affects $5.8 \%$ of men in the same age range (14).

Depression in pregnancy is defined as at least eight symptoms for a period of at least two weeks. It has been noted that women who are pregnant may attribute some symptoms of depression to symptoms of pregnancy, like fatigue, sadness, irritability, lack of appetite, and this may lead to lower incidences of depression reported among pregnant women (15). There may also be societal and family pressure to have an feelings of bliss during pregnancy which may also lead to underreporting of prenatal depression (15).

There are known risk factors associated with depression during pregnancy: low self-esteem, prenatal anxiety, low social support, other major life events, low incomes, history of abuse, and others $(16,17)$. Prenatal depression is also considered a mediator in the development of Postnatal depression, which is a predictor for Parenting Stress (16). 


\subsection{Effects of Depression on Pregnancy}

The reviewed papers and studies assessed the effects of depression as it affects birth weight. Birth weight is typically categorized as follows: Very Low Birth Weight $<1500$ grams, Low Birth Weight 1500-2500 grams, Normal 25004000 grams, Heavy Birth Weight 4000 grams or greater (18). It is suggested that the incidence of depression changes with trimesters, $11 \%$ in the first trimester and $8.5 \%$ in the second and third trimesters (15).

\subsubsection{Association Between Prenatal Depression and Low Birth Weight}

An association between prenatal depression and low birth weight was seen in some of the studies reviewed. One study determined that there was a significant association between being black and depressed and having a higher rate of premature births and low birthweight deliveries (8). The study also found that depressed pregnant mothers would answer positively to three questions 1) having a stressful situation during pregnancy, 2) not being happy when they found out they were pregnant, and 3) their partners were not happy that they were pregnant (8). The cohort studies were internationally based, one in Israel and one in Vietnam $(9,11)$. The Israeli study also found that women who screened positive for prenatal depression were older (26-38 years of age versus 22-34 years of age) and had a higher gravidity (4 versus 3 ) (11). The study based in Vietnam concluded that maternal age over 25 was associated with higher risks of prenatal depression (9). Two meta analysis showed between prenatal 
depression and increased risk of preterm birth and $\operatorname{LBW}(1,10)$. The risk for preterm delivery and low birth weight increased with severity of depression (10). One of the meta analyses also found that magnitude of effect associated with prenatal depression was dependent on country location and socioeconomic status (1). Only one of the reviewed studies assessed race (8).

Table 1. Association Between Prenatal Depression and Low Birth Weight

\begin{tabular}{|c|c|c|c|}
\hline Study Name & Study Type & Association & Results \\
\hline $\begin{array}{l}\text { Depressed pregnant black } \\
\text { women have a greater } \\
\text { incidence of prematurity } \\
\text { and low birthweight } \\
\text { outcomes (8) }\end{array}$ & Cohort & + & $\begin{array}{l}\text { Association between being black } \\
\text { and depressed and having a } \\
\text { higher rate of premature births } \\
\text { and low birthweight deliveries } \\
\text { (Fvalue }=5.27 \text {, Pvalue }=0.05 \text { ) }\end{array}$ \\
\hline $\begin{array}{l}\text { Is antenatal depression } \\
\text { associated with adverse } \\
\text { obstetric and prenatal } \\
\text { outcomes? (11) }\end{array}$ & $\begin{array}{l}\text { Retrospective } \\
\text { Cohort }\end{array}$ & + & $\begin{array}{l}\text { Women diagnosed with } \\
\text { depression during pregnancy } \\
\text { were at an increased risk for } \\
\text { preterm birth ( } p \text {-value }<0.001 \text { ) }\end{array}$ \\
\hline $\begin{array}{l}\text { Symptoms of antenatal } \\
\text { common mental } \\
\text { disorders, preterm birth } \\
\text { and low birthweight: a } \\
\text { prospective cohort study } \\
\text { in a semi-rural district of } \\
\text { Vietnam (9) }\end{array}$ & $\begin{array}{l}\text { Prospective } \\
\text { community- } \\
\text { based cohort } \\
\text { study }\end{array}$ & + & $\begin{array}{l}\text { A correlation between } \\
\text { depression and preterm birth, } \\
\text { (OR: } 1.98 \text { [95\% Cl, } 1.14-3.43] \text { ), } \\
\text { and LBW (OR } 2.24 \text { [95\% Cl, } \\
1.02-4.95])\end{array}$ \\
\hline $\begin{array}{l}\text { A Meta-analysis of } \\
\text { Depression During } \\
\text { Pregnancy and the Risk of } \\
\text { Preterm Birth, Low Birth } \\
\text { Weight, and Intrauterine } \\
\text { Growth Restriction (1) }\end{array}$ & Meta Analysis & + & $\begin{array}{l}\text { Association between prenatal } \\
\text { depression and preterm birth } \\
\text { (RR } 1.39(95 \% \mathrm{Cl}, 1.19-1.61) \\
\text { and LBW (RR } 1.49(95 \% \mathrm{Cl} \text {, } \\
1.25-1.77))\end{array}$ \\
\hline $\begin{array}{l}\text { Untreated Depression } \\
\text { During Pregnancy: Short } \\
\text { and Long-Term Effects in } \\
\text { Offspring. A Systematic } \\
\text { Review. (10) }\end{array}$ & Meta Analysis & + & $\begin{array}{l}\text { Association between prenatal } \\
\text { depression and increased risk of } \\
\text { preterm birth (OR of } 1.56 \text { [95\% } \\
\mathrm{CI}, 1.25-1.94 ; 14 \text { studies; } 12 \text {, } \\
\text { measure of heterogeneity, } 39 \%] \text { ) } \\
\text { and LBW (OR of } 1.96 \text { [95\% Cl, } \\
1.24-3.10 ; 8 \text { studies; } 12,48 \%] \text { ) }\end{array}$ \\
\hline
\end{tabular}




\subsubsection{No Association Between Prenatal Depression and Low Birth Weight}

No association between prenatal depression and low birth weight was seen in some of the studies reviewed. Studies in Pakistan and Greece both showed no association $(3,4)$. The Pakistani study was done in a rural location and the lack of association was contributed to more urban population being represented in this study than other, more rural studies that had been done in Pakistan (3). The Grecian study had a lack of applicability as the study population was comprised of adults of a higher socioeconomic status, who were mostly graduates of higher education, and who had prenatal care (4). A Meta Analysis of 30 studies did not find a correlation between prenatal depression and low birthweight(2). The Meta Analysis also found no association between depression and Neonatal Intensive Care admissions, preeclampsia, gestational age, or APGAR scores (both 1 and 5 minutes) (2).

Table 2. No Association Between Prenatal Depression and Low Birth Weight

\begin{tabular}{llll}
\hline Study Name & Study Type & Association & Results \\
\hline Antenatal Depression Is Not & Cohort & - & A significant association with \\
Associated With Low-Birth & & between prenatal depression \\
Weight: A Study From Urban & & and low birth weigh was not \\
Pakistan (3) & & found, OR of $0.881(95 \% \mathrm{Cl}$ \\
& & $0.732-1.060)$. \\
\hline
\end{tabular}


Table 2, continued. No Association Between Prenatal Depression and Low Birth I

\begin{tabular}{|c|c|c|c|}
\hline Study Name & Study Type & Association & Results \\
\hline $\begin{array}{l}\text { Limited Depressive And } \\
\text { Anxiety Symptoms Late In } \\
\text { Pregnancy Are Not Related } \\
\text { To Neonatal Outcomes (4) }\end{array}$ & Cohort & - & $\begin{array}{l}\text { A statistically significant } \\
\text { correlation was not found } \\
\text { between prenatal depression } \\
\text { and the following neonatal } \\
\text { outcomes: birth weight (Pvalue = } \\
0.872) \text {, Apgar score (Pvalue = } \\
0.434 \text {, and admission in neonata } \\
\text { intensive care unit (Pvalue = } \\
0.918)\end{array}$ \\
\hline $\begin{array}{l}\text { The Impact Of Maternal } \\
\text { Depression During } \\
\text { Pregnancy On Prenatal } \\
\text { Outcomes: A Systematic } \\
\text { Review And Meta-Analysis. } \\
\text { (2) }\end{array}$ & $\begin{array}{l}\text { Meta } \\
\text { Analysis }\end{array}$ & - & $\begin{array}{l}\text { No Correlation Between Prenata } \\
\text { Depression And Low Birthweight } \\
\text { (Or = } 1.21 \text {, } \\
P=0.195[95 \% \mathrm{Ci}, 0.91,1.60] \text { ) }\end{array}$ \\
\hline
\end{tabular}

\subsubsection{Other Outcomes}

Other birth outcomes were seen to be associated with prenatal depression in some of the studies reviewed. Increased fetal growth retardation, increased preterm births, and decreased APGAR scores were seen in a study based on a middle-income population in Pakistan (7). In Sweden, a study found no correlation with maternal prenatal depression and traditional neonatal outcomes, low birth weight and preterm delivery, but did find a non significant association with heavy birth weights (identified as greater than 4000 grams). (5) The Swedish study noted depression is typically assessed once during pregnancy, meaning that cases of depression could be missed if the screening happened too soon in the pregnancy (5). A greater incidence of premature delivery and low birthweight was associated with prenatal depression in a Miami, Florida based study. Elevated prenatal cortisol levels were observed in the depressed women in the 
Miami population and the depressed women also had fetuses who were smaller and had lower birth weights (6). As discussed above, premature delivery can be associated with prenatal depression (1,5-11). Premature, or pre-term, delivery is defined as less than 37 total gestation weeks (18).

A systematic review of prenatal depression and both gestational age and birthweight found less than a fourth of the 50 published reports reviewed found prenatal depression associated with pre-term births (19). In contrast the authors found over half of the reports found prenatal depression associated with low birthweight (19). The authors believe that the effects of prenatal depression on pre-term birth are less consistent than the effects of prenatal depression on low birth weight, but note that further research is needed (19).

Table 3. Other Outcomes

\begin{tabular}{|c|c|c|c|}
\hline Study Name & Study Type & Other Outcomes & Results \\
\hline $\begin{array}{l}\text { Effect of antenatal } \\
\text { depression on maternal } \\
\text { dietary intake and } \\
\text { neonatal outcome: a } \\
\text { prospective cohort (7) }\end{array}$ & $\begin{array}{l}\text { Hospital-based, } \\
\text { prospective } \\
\text { cohort study }\end{array}$ & $\begin{array}{ll}\text { - } & \text { Fetal Growth } \\
& \text { Retardation } \\
\text { - } & \text { Increased } \\
& \text { Preterm Births } \\
& \text { decreased } \\
\text { - } & \text { APGAR } \\
& \text { scores }\end{array}$ & $\begin{array}{l}\text { Women who were prenatally } \\
\text { depressed have a poor dietary } \\
\text { intake (RR of } 2.58(95 \% \mathrm{Cl} \\
1.60-5.23)) \text { increased Fetal } \\
\text { Growth Retardation (RR of } 2.70 \\
(95 \% \mathrm{Cl} 0.69-3.70)) \text {, increased } \\
\text { Preterm Births (RR of } 1.60 \\
(95 \% \mathrm{Cl} 0.72-2.45)) \text {, and } \\
\text { decreased APGAR scores (RR } \\
\text { of } 2.70(95 \% \mathrm{Cl} 0.69-3.70))\end{array}$ \\
\hline $\begin{array}{l}\text { Neonatal Outcome } \\
\text { following Maternal } \\
\text { Antenatal Depression } \\
\text { and Anxiety: A } \\
\text { Population-based Study } \\
\text { (5) }\end{array}$ & Cohort & $\begin{array}{l}\text { - Heavy Birth } \\
\text { Weights }\end{array}$ & $\begin{array}{l}\text { No correlation with maternal } \\
\text { prenatal depression and } \\
\text { traditional neonatal outcomes, } \\
\text { low birth weight and preterm } \\
\text { delivery; a non significant } \\
\text { association between prenatal } \\
\text { depression and Heavy Birth } \\
\text { Weights (identified as greater } \\
\text { than } 4000 \text { grams) with an OR of } \\
1.17(95 \% \text { Cl } 0.60-2.27)\end{array}$ \\
\hline
\end{tabular}


Table 3, continued. Other Outcomes

\begin{tabular}{llll}
\hline Study Name & Study Type & Other Outcomes & Results \\
\hline $\begin{array}{lll}\text { Prenatal depression } \\
\text { restricts fetal growth (6) }\end{array}$ & Case Control & - Premature & Prenatal depression was \\
& & Delivery & statistically associated with a \\
& & greater incidence of premature \\
& & delivery, OR of 2.6, and a \\
& & greater incidence of low \\
& & birthweight, OR of 4.75 \\
\hline
\end{tabular}

\subsection{Prenatal Depression and Ethnicity}

Ethnicity is often used as a study variable as it implies shared genetic and social constructs among those in an ethnic group. Race can be used as a genetic qualifier: white, black, etc., but it lacks the social aspect brought in by using ethnicity. There are some international studies that have looked at ethnicity and its interaction with prenatal depression. A cohort study in Oslo, Norway assessed depression in pregnancy and looked at the prevalence and risk factors in a multiethnic population (20). The study found that the higher risks of prenatal depression were seen in the Middle Eastern and South Asian populations (20). The Norwegian study assessed ethnicity with its traditional definition, as given above. A community clinic based study in Washington State assessed the ethnic and racial differences in the prevalence of depression (21). This study found that in its population prenatal depression was higher among Black women and Latinas and lower among non-Hispanic White women (21). This study also found factors that were associated with prenatal depression were: high levels of psychological stress, prenatal domestic violence, lower levels of education, and having preexisting medical conditions (21). The Washington State study used a mix of the ethnicity and race variables which makes interpretation of the results 
difficult. A U.S. cohort study considered the sociodemographic predictors of prenatal depressive symptoms (22). The U.S. cohort found that Black and Hispanic women had a higher prevalence of depressive symptoms (22). The U.S. cohort study also used a mix of the ethnicity and race variables which makes interpretation of the results difficult.

A systematic review of the literature showed a higher prevalence of prenatal depression among non-Hispanic Blacks and Hispanics compared to non-Hispanic Whites (23). It was found that few of the studies reviewed had looked a the correlated of prenatal depression by ethnicity (23).

Table 4. Prenatal Depression and Ethnicity

\begin{tabular}{|c|c|c|c|}
\hline Study Name & Study Type & Variable & Results \\
\hline $\begin{array}{l}\text { A prospective cohort } \\
\text { study of depression in } \\
\text { pregnancy, prevalence } \\
\text { and risk factors in a } \\
\text { multi-ethnic population } \\
\text { (20) }\end{array}$ & $\begin{array}{l}\text { Prospective } \\
\text { Cohort }\end{array}$ & Ethnicity & $\begin{array}{l}\text { Higher risks of prenatal } \\
\text { depression were seen in the } \\
\text { Middle Eastern (OR }=2.81, \\
(95 \% \mathrm{Cl} 1.29-6.15) \text { and South } \\
\text { Asian }(\mathrm{OR}=2.7295 \% \mathrm{Cl} \\
1.55-5.48) \text { populations }\end{array}$ \\
\hline $\begin{array}{l}\text { Racial differences in the } \\
\text { prevalence of antenatal } \\
\text { depression (21) }\end{array}$ & Descriptive & $\begin{array}{l}\text { A mix of race } \\
\text { and ethnicity }\end{array}$ & $\begin{array}{l}\text { Prenatal depression was higher } \\
\text { among Black women }(15.3 \%) \\
\text { and Latinas }(6.3 \%) \text { and lower } \\
\text { among non-Hispanic White } \\
\text { women }(3.6 \%)\end{array}$ \\
\hline $\begin{array}{l}\text { Sociodemographic } \\
\text { predictors of antenatal } \\
\text { and postpartum } \\
\text { depressive symptoms } \\
\text { among women in a } \\
\text { medical group practice } \\
\text { (22) }\end{array}$ & Cohort & $\begin{array}{l}\text { A mix of race } \\
\text { and ethnicity }\end{array}$ & $\begin{array}{l}\text { The prevalence of depressive } \\
\text { symptoms in pregnant women } \\
\text { was } 9 \% \text { in the study population. } \\
\text { Black (15\%) and Hispanic } \\
(16 \%) \text { women had a higher } \\
\text { prevalence of depressive } \\
\text { symptoms. }\end{array}$ \\
\hline
\end{tabular}




\subsection{Prenatal Depression in Refugee Populations}

Refugees experience unique life factors that make them more vulnerable to both prenatal and postnatal depression. $(24,25)$. An Australian study looked at the factors that affect the implementation of prenatal depression screening for women of refugee backgrounds, as the prevalence of prenatal depression among this population is poorly documented (25). The study found that participants recognized a need for mental health screening, although this may have been due to selection bias meaning those who participated were more likely to understand the need for screening (25). Des Moines, lowa has been an official refugee resettlement city since 1975, resettling people from Southeast Asia, Eastern Europe, Africa and the Middle East (26).

\subsection{Edinburgh Postnatal Depression Scale (EPDS)}

The Edinburgh Postnatal Depression Scale (EPDS) was originally created in the United Kingdom and was used to screen for postnatal depression. Since its creation, EPDS has become an international screening tool for assessing the symptoms of prenatal depression, postnatal depression, and anxiety (27). There are studies that assess the reliability and validity of EPDS in a variety of situations.

One systematic review assessed the reliability and validity of the EPDS for detecting prenatal common mental disorders (PCMD) among women in low- and lower-middle-income countries (28). It was found that the local language versions 
(where EPDS was translated into local languages) had lower precision for identifying the true cases of PCMD compared to the original English version (28). Most of the local language versions of the EPDS assessed did not meet the criteria for the formal evaluation of a screening instrument. The authors found that when the diagnostic interviews for EPDS were done in the local language, questions may not have been understood as the questions were not culturally adapted (28).

Another systematic review, a Meta-Analysis, assessed the reliability and validity of EPDS in African settings (29). There was a pooled sensitivity of 0.94 $(95 \% \mathrm{Cl} 0.68,0.99)$ and a pooled specificity of $0.77(95 \% \mathrm{Cl} 0.59,0.88)(29)$. The authors found that the EPDS could reliably and validly assess prenatal depression symptom severity (median estimated coefficient alpha 0.84 (IQR $0.71,0.87))(29)$.

1.6 Healthy Start

Healthy Start was started in the United States to reduce the rate of infant mortality and to improve prenatal outcomes. It is primarily for women who live in areas of high infant mortality. Healthy start does is not limited to one ethnicity nor does it base its services off of immigration status. It is funded both by federal and state governments. The Healthy Start program also screens women for depression using the EPDS with the goal of connecting women who screen positive with needed resources. It has been found women who delivered infants 
after the Healthy Start program began were $85 \%$ less likely to deliver preterm babies than women giving birth before the program began, showing that the healthy program is an effective program (30). One study showed that there is no change in the level of depressive symptoms or depressive treatment in a population before and after Healthy Start (31). There are many cultural stigmas that surround the topic of depression and since Healthy Start is an ethnically diverse program in areas of high infant mortality and low socioeconomic status, this may play a role in the diagnosis and treatment rates seen in this population (32). Few studies have assessed the Healthy Start population and depression (30-33).

\subsection{Conclusions}

The studies are not conclusive when it comes to the birth effects of prenatal depression. The populations of the studies varied greatly in location, socioeconomic status, prenatal care. As some of these variables are also considered risk factors in developing prenatal depression this makes any conclusions from comparing the studies weak.

The clinical diagnosis of depression can include altered appetite (along with other symptoms) and the study (7) that shows women with prenatal depressing have poorer nutritional intakes, all non-normal, atypical, birth weights should be looked at when assessing for an association with prenatal depression. Many studies assess for and suggest that low birth weights are associated with 
prenatal depression, but those studies do not look at separating out the heavier birth weights from the "normal" and so are potentially not assessing an affected group of birth weights that could be associated with depression.

It is also of interest that though there studies from populations across the globe $(3-5,7,9,11)$ only one study actually looked at how Race plays a role in both prenatal depression and birth weights (8). Race and Ethnicity are important factors in the population wide determination of birth weights (18), it stands to reason that they would be important factors in any analysis that includes birth weights as an outcome. Another variable to consider is gestational age. Even though it does not have as strong of an association with prenatal depression as birthweight does, it still has been shown to be associated with the adverse birth outcomes seen with prenatal depression $(1,5-11,19)$.

Among the studies that looked at racial or ethnic differences in the prevalence of prenatal depression, it was found that Black and Hispanic women had a higher prevalence of prenatal depression than White women (21-23). One study looked at global ethnicities, however this study was based in Norway (20). It has also been found that prenatal depression among refugee women has been poorly documented, even though they have unique life stressors that make them more vulnerable to prenatal depression $(24,25)$. Des Moines, lowa is a city in the United States that has resettled refugees for over 40 years (26). 
The EPDS has been validated for prenatal depression screening (27). It has also been validated globally, though there is some concern in the effective translation of the EPDS into local languages $(28,29)$.

The Healthy start population is a unique population of women. Women are a part of the program based solely on living in areas of high infant mortality. The women are screened for depression using EPDS. Few studies have been done using data from this population (30-33). 


\section{AIMS AND HYPOTHESIS}

\subsubsection{Aim 1:}

To determine whether screening positive for depression is associated with atypical birth weights

\subsubsection{Aim 2:}

To determine whether specific ethnicities play a role in the determination of being screened positive for depression.

\subsubsection{Hypothesis 1:}

Screening positive for depression is positively associated with atypical birth weights.

\subsubsection{Hypothesis 2:}

There is an interaction between specific ethnicities and being screened positive for depression. 


\section{MATERIALS AND METHODS}

\subsection{Study Population}

This study will be conducted using data from a patient population found in Des Moines, Polk County, lowa though Healthy Start and the Visiting Nurse Services (VNS). The Healthy State program was created with the goals of reducing infant mortality. The VNS is a voluntary clinical services program whose goals are also to reduce infant mortality and morbidity. The VNS Empowerment program has been working through the Healthy Start program which began in 1997. Healthy Start is funded through the US Department of Health and Human Services, Maternal and Child Health Bureau. The state of lowa has been supporting the VNS Empowerment Family Support Program since 1998. Empowerment expands Healthy Start services to children $>2$ years old.

Healthy Start and Empowerment case managers, who speak a total of 22 different languages and dialects, provide comprehensive support to families through home visiting; prenatal, postpartum, and parenting education; child development screening and education; support groups; prenatal depression screening and referral; English as a Second Language (ESL) classes, including 
transportation and child support for the classes; and opportunities for parent education and involvement.

The patient population eligible to be a part of Healthy Start live within the nine ZIP code range. Prior to every grant cycle, Healthy Start reviews the current Census and birth-death registration data to ensure they are targeting the highest need ZIP Code areas based on infant mortality and other key indicators of being at a high risk for poor maternal and child health outcomes.

Women who are eligible by location become a part of Healthy Start and VNS Empowerment through a variety of ways including both walk in referrals and outside referrals. Case managers visit the women who are a part of the Healthy Start and VNS Empowerment program and provide a variety of services, including depression screening services.

\subsection{Exposure}

Women who were a part of Healthy Start and who were either pregnant or had a child under 2 years of age were eligible for depression screening. The depression screening was done using the Edinburgh Postnatal Depression Scale (EPDS). The EPDS has been found to be a feasible screening tool for both prenatal and postpartum depression (34). EPDS in Healthy Start is provided by a case manager. The first screening occurs at program intake and subsequent 
screenings occur at various points during and after pregnancy. EPDS is a questionnaire that asks the following 10 questions, based in the last two weeks:

1. I have been able to laugh and see the funny side of things.

2. I have looked forward with enjoyment to things.

3. I have blamed myself unnecessarily when things went wrong

4. I have been anxious or worried for no good reason.

5. I have felt scared or panicky for no very good reason.

6. Things have been getting on top of me.

7. I have been so unhappy that I have had difficulty sleeping.

8. I have felt sad or miserable.

9. I have been so unhappy that I have been crying.

10. The thought of harming myself has occurred to me.

If a person is comfortable with English, Spanish or Arabic and is literate, they will be given the written form. If a person is illiterate or does not know one of those three languages then the EPDS will be given orally through a trained interpreter. When translators and EPDS translations are available, EPDS is administered in a person's preferred language. Scores from the EPDS questionnaire can range from 0 to 30 . The Des Moines Healthy Start program uses 12 as the minimum score for a positive depression screen. If a person screens positive, they are referred to appropriate health professionals for treatment.

\subsection{Outcome}

Infant birthweight and gestational age are reported though forms given to participants upon program intake and/or after the birth of a child. Birthweight is given in grams and will be dichotomized into two separate variables. Birthweight 
cutoff values will be based on federal recommendations (18). Gestational age is given in weeks and will be dichotomized into one variable. Pre-term and full-term cut offs will be based on federal recommendations (18).

\subsection{Other Variables}

Race and Ethnicity are self reported and collected by the Healthy Start program. There are six different races reported: white, black or African American, Asian, American Indian or Alaska Native, Native Hawaiian or Pacific Islander, and other. Ethnicities were more broadly reported and so they have been reorganized by region: American, African, Hispanic/Latino, Asian, European, and other. A variable named, immigrant status will be used to define if a person has American origins or not. The variable immigrant status has nothing to do with wether a person is an immigrant or a refugee, those variables were not reported. Language based variables will be used to help quantify the diversity of this population: English as a primary language and primary language by region of origin.

Other variables will be assessed as they are known to influence depression, birthweight, and/or gestational age: age, smoking status, consumption of alcohol, pregnancy intention, and previous pregnancies. 


\subsection{Statistical Analysis}

Statistical Analysis will be performed using STATA 14 and SAS 9.4. Associations between atypical birth weights and depression, the primary exposure, will be calculated by logistic regression modeling that is adjusted for interaction or confounder variables as needed. Associations between depression and ethnicities and races will be assessed by calculating Chi-Square p-values. All statistical screens of hypothesis used will be two-tailed and have alpha, type 1 error, set at $5 \%$. 


\section{RESULTS}

\subsection{Population}

The study sample was taken from women who have been participants in the Healthy Start Program based in Des Moines, lowa. The women in this study population were screened for depression using EPDS upon admission into the program. They were also screened for depression while pregnant, sometimes in more than one trimester. The depression screen score used in this analysis was based upon the first screen done during pregnancy, regardless of which trimester that screen occurred. Women who did not have a gestational length or birthweight listed for their child were excluded from this study. The following had both gestational length and birthweight listed: 305 were first screened in the 1st trimester, 621 were first screened in the 2 nd trimester, and 167 were first screened in the 3rd trimester. Of the women included in the study, 977 screened negative with EPDS screening for prenatal depression and 116 screened positive with EPDS screening for prenatal depression. The total sample size used in the calculations for this analysis was 1093 , Figure 1 . The prevalence of screening positive for depression in this study population was $15.2 \%$. 
Figure 1: Flow chart showing sample size selection

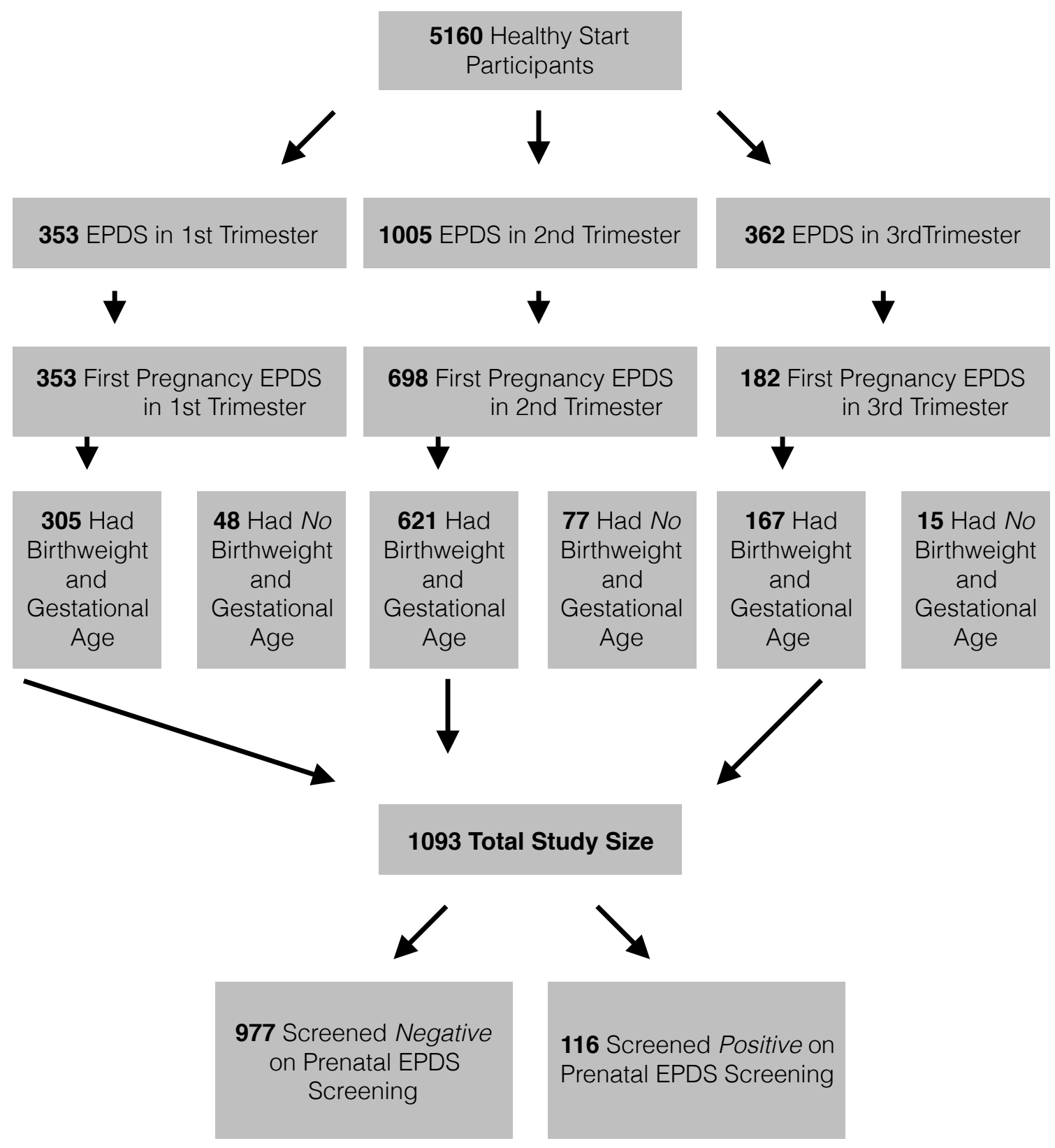


The mean age in this population was 33.7 years. The mean age of those who screened negative was one year younger than those who screened positive, 33.6 and 34.5, respectively, Figure 2 .

Figure 2: Age distribution by EPDS screen results

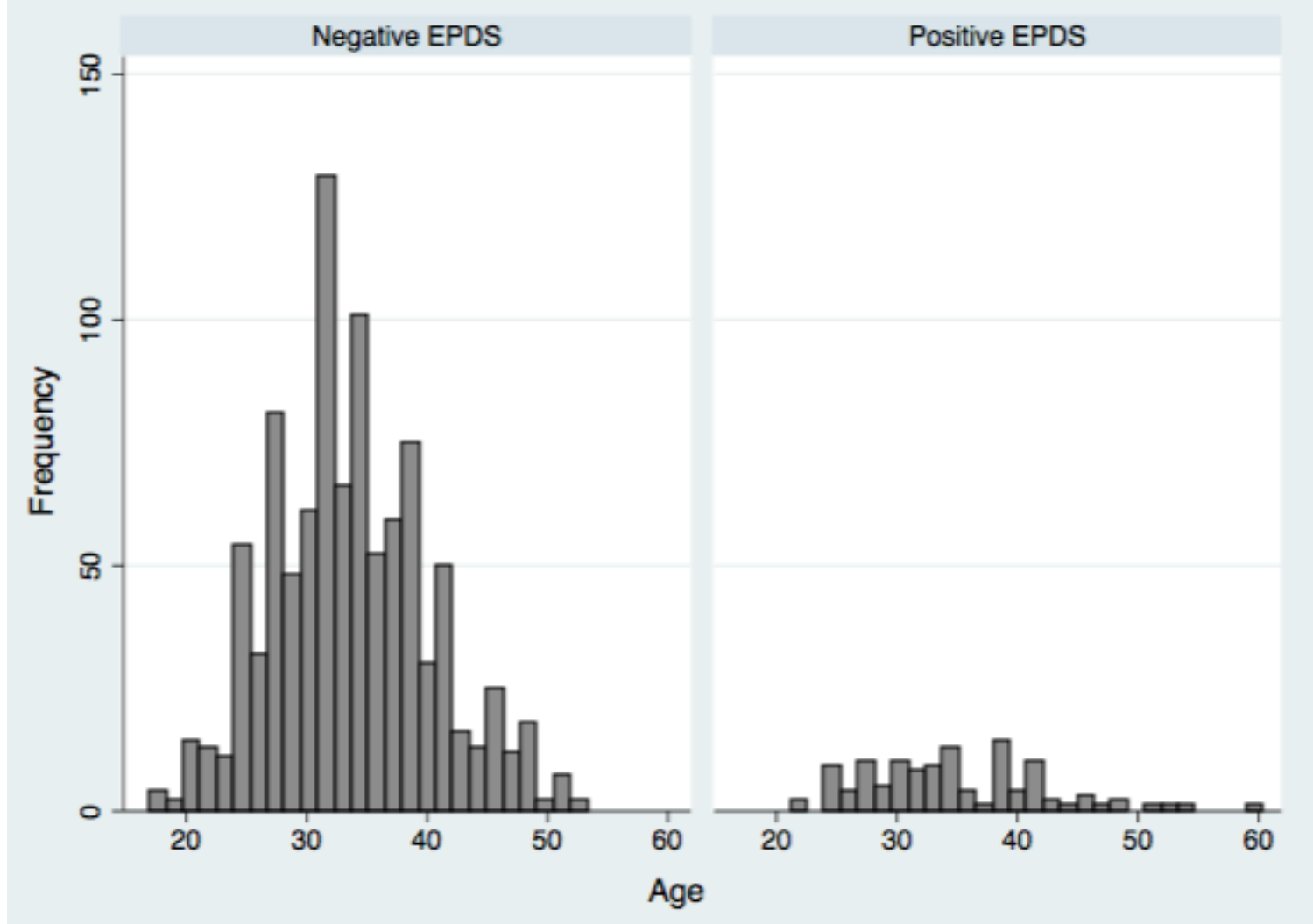

The variables of race and ethnicity were recorded for all participants. White was the most common race among those who screened positively (41.5\%) and those who screened negatively (62.1\%). Black or African American was next highest among those who screened positive (21.6\%), while Asian was next highest among those who screened negative (33.3\%), Table 5. Ethnicity was broken up by region of origin. Asian women were the largest group who screened negative 
(32.0\%) while American women were the largest group who screened positive, (44.0\%) Table 5, Figure 3.

Figure 2: Age distribution by EPDS screen results

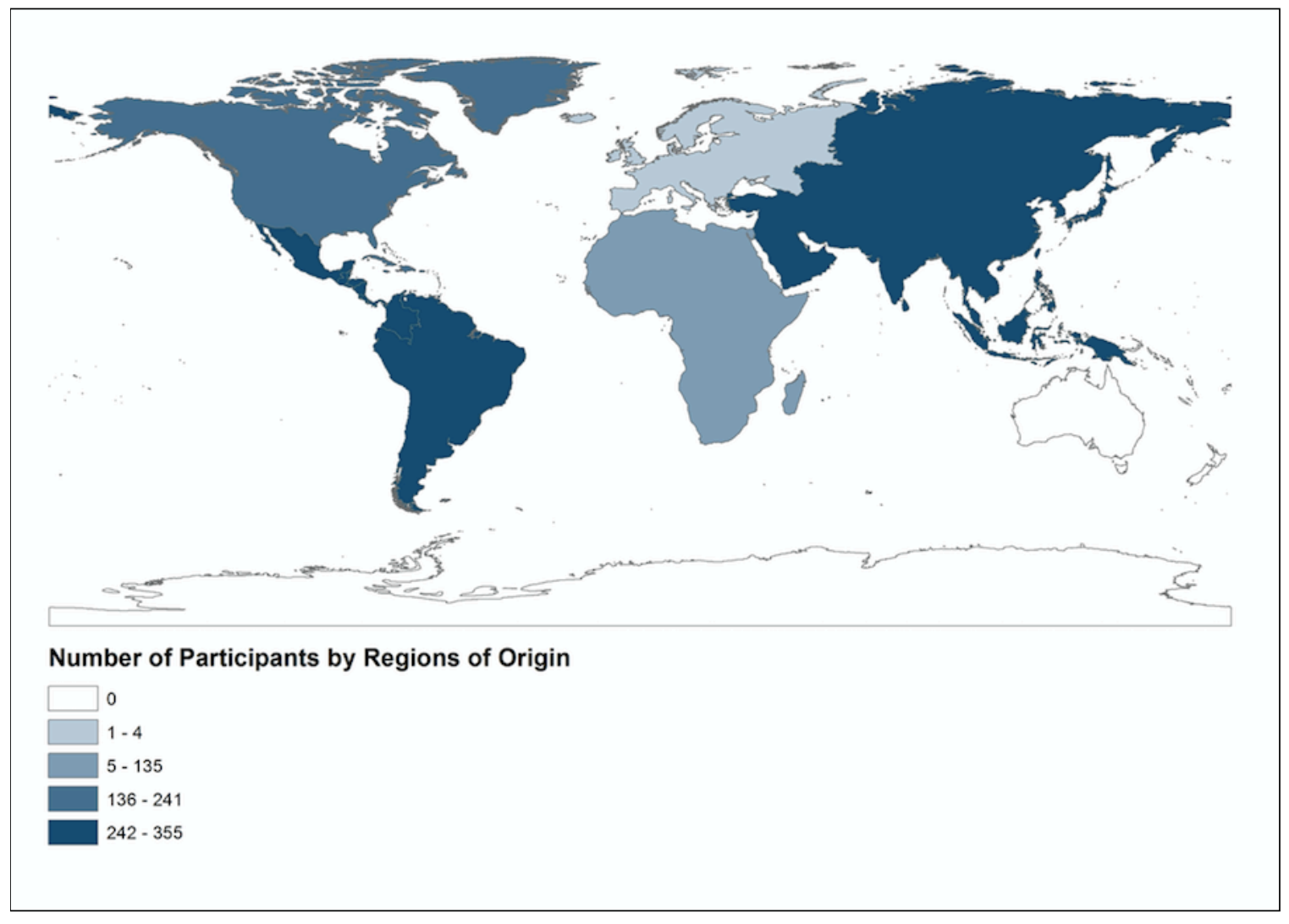

A majority of all those screened were non-Americans, $80.5 \%$ of those who screened negatively and $56.0 \%$ of those who screened positive, Table 5 . Those who screened negative were more likely to not speak english as a primary language $(75.6 \%)$, Table 5. English was the primary language of just over half of those who screened positive in the EPDS screening (53.5\%), Table 5. Language was also split by region of origin. Asian languages were more common among 
those who screened negative (32.2\%) while North American languages were more common among those who screened positive (53.4\%) Figure 4.

Figure 4: Country of Primary Language Spoken

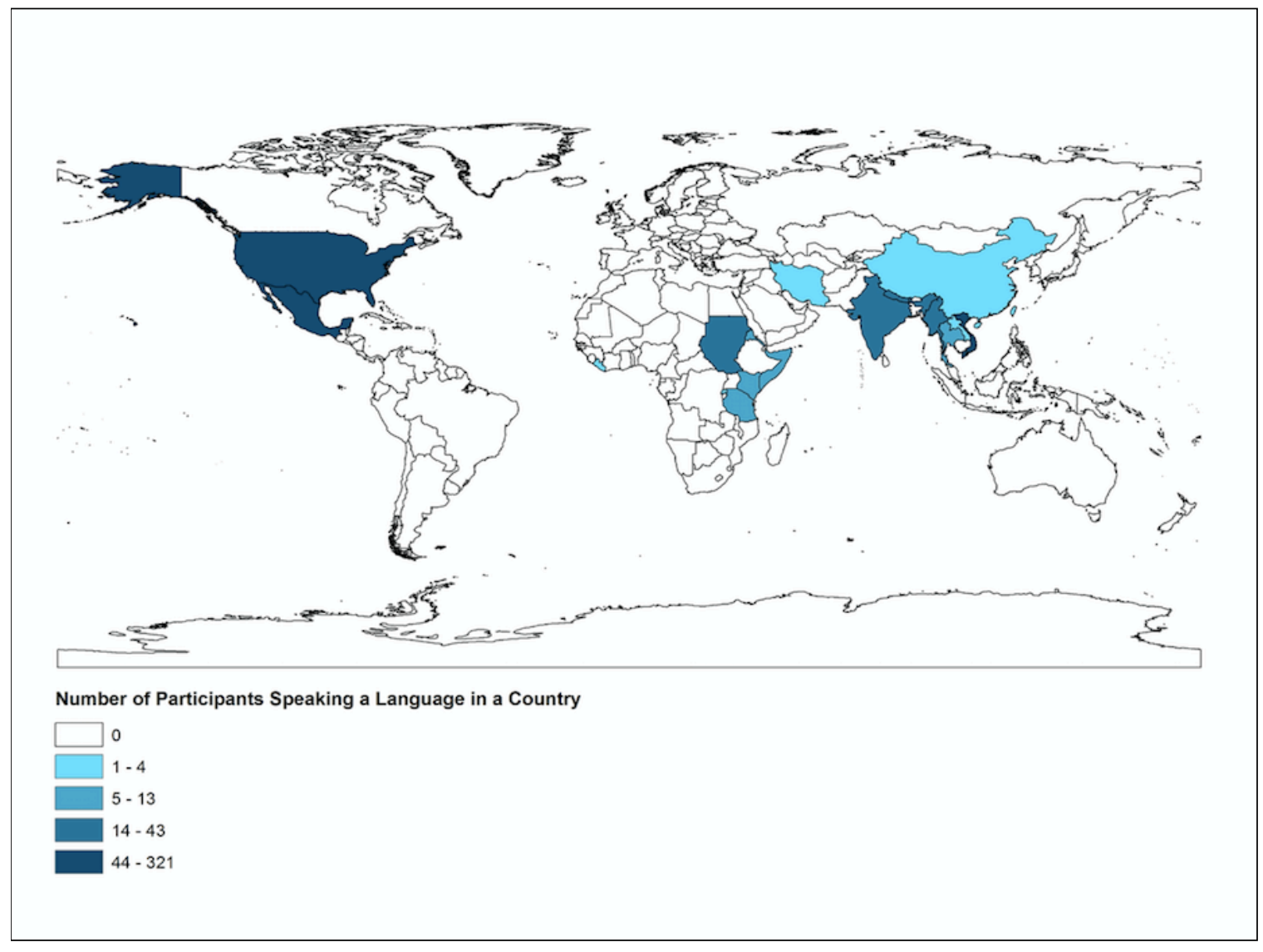

The minimum number of previous pregnancies ranged from zero to thirteen in the total sample population. Having no previous pregnancies or one previous pregnancy was most common among those who screened negative. One or two pregnancies were most common among those who screened positive, Figure 5. 
Figure 5: Previous Pregnancy distribution by EPDS screen results

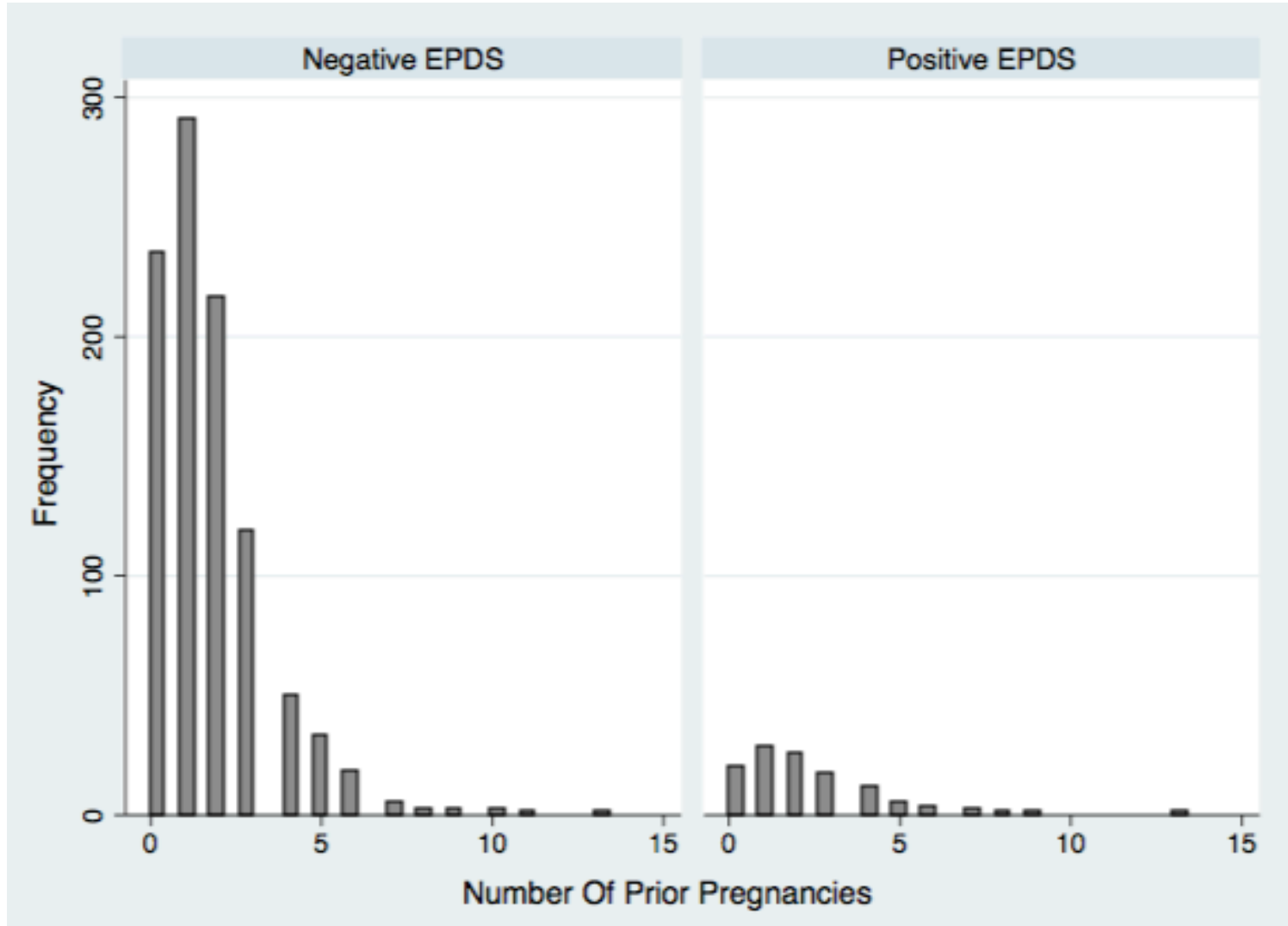

The majority of those screened did not smoke, although a higher percentage of those who screened positive smoked than those who screened negative, $17.2 \%$ and $9.4 \%$ respectively, Table 5 . A similar pattern was seen in those who consumed alcohol, where $10.3 \%$ of people who screened positive reported alcohol consumption and 2.4 of people who screened negative reported alcohol consumption, Table 5.

The mean birthweight of children born to participants was 3213.91 grams. Among those who screened positive the mean infant birthweight was 3205.77 
grams and among those who screened negative the mean infant birthweight was 3214.88, Figure 6.

Figure 6: Birthweight, in grams, by EPDS screen results

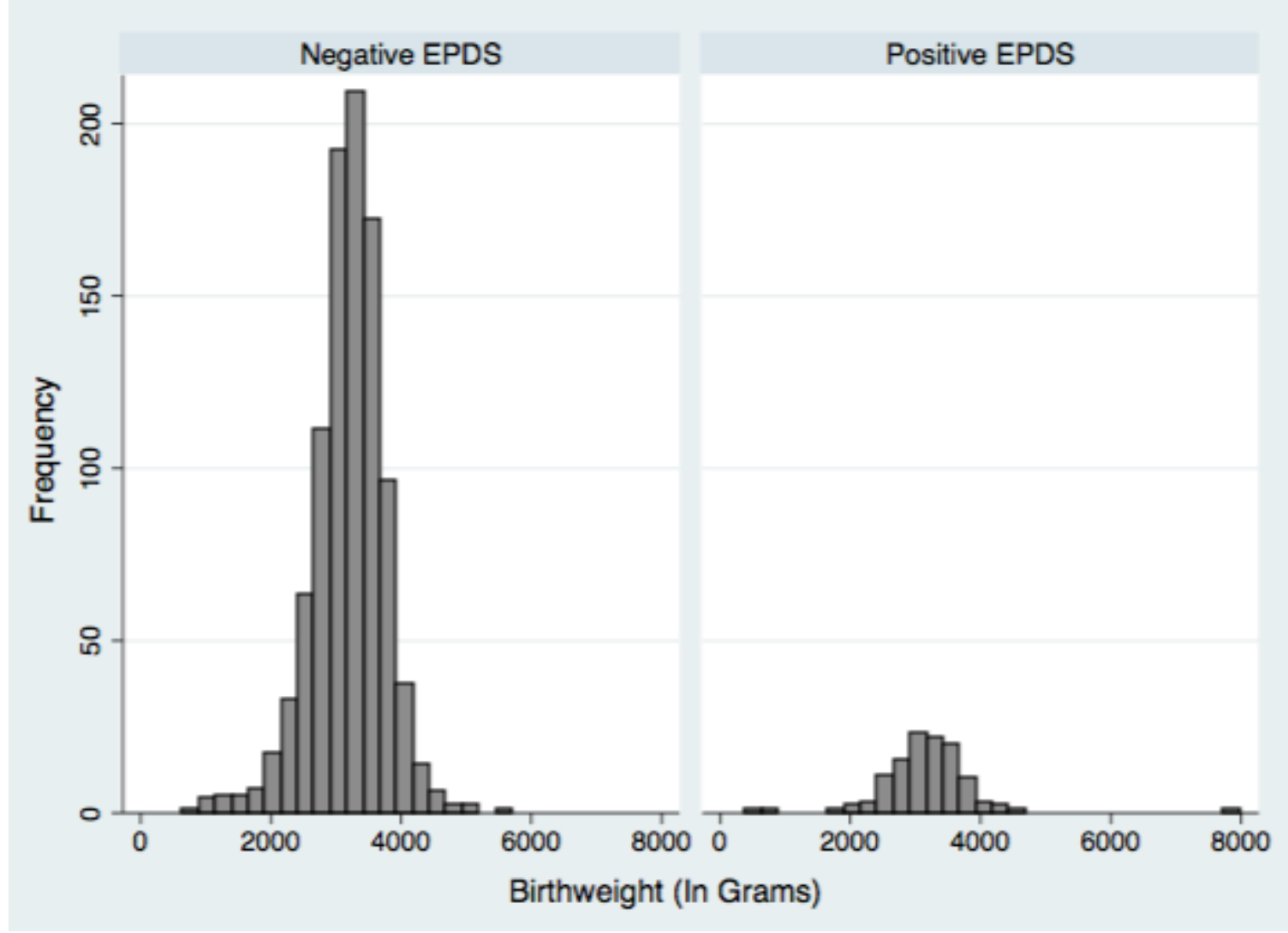

The mean gestational age of children born to participants was 39 weeks. The mean gestational age of children born to participants was almost a week longer among those who screened negative compared to those who screened positive, 39.1 weeks and 38.5 weeks, respectively, Figure 7. 
Figure 7: Gestational Age, in weeks, by EPDS screen results

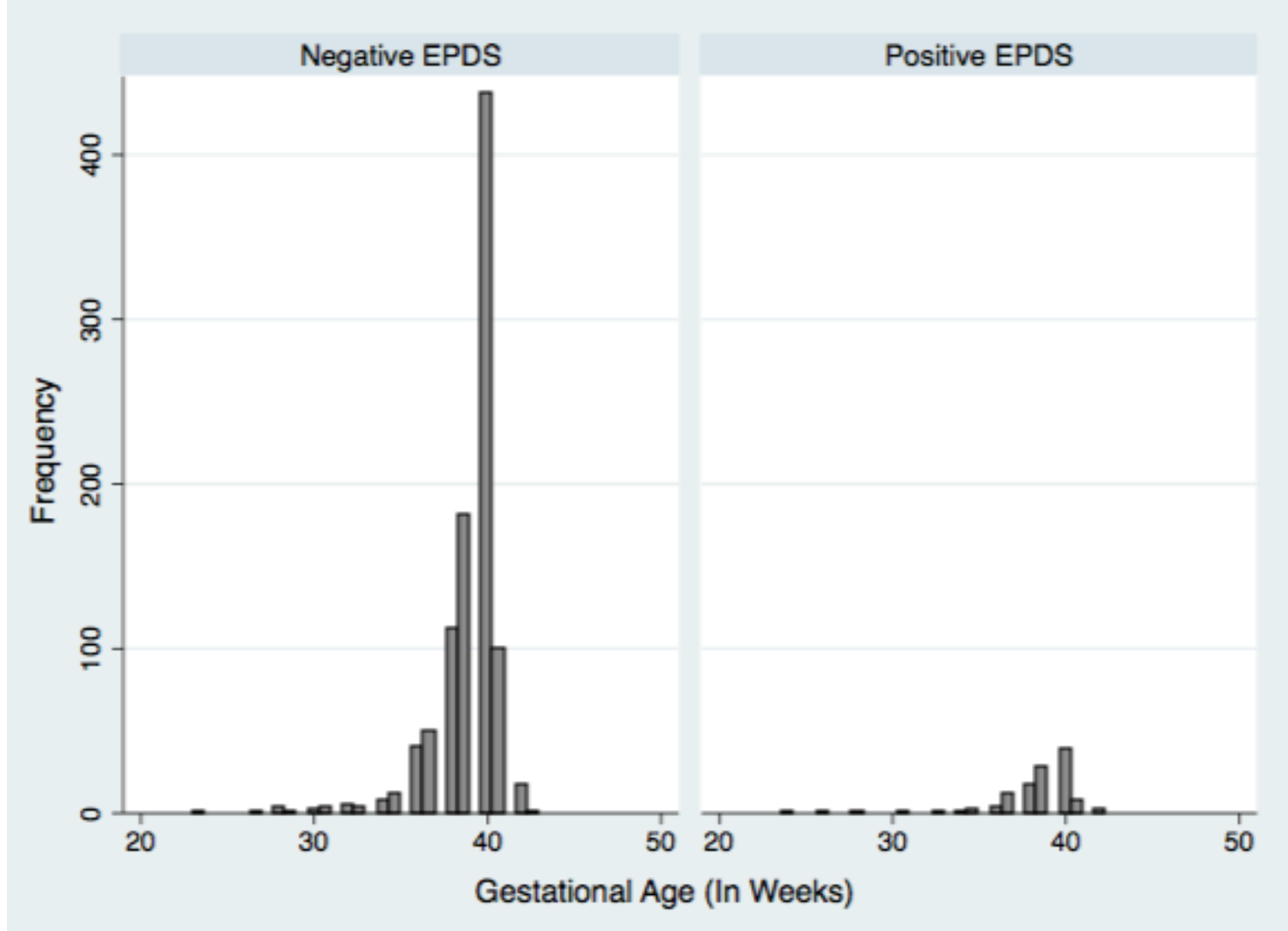

Table 5, Descriptives for the Study Population

\begin{tabular}{lcc}
\multicolumn{1}{c}{ Characteristics } & $\begin{array}{c}\text { Not Depressed } \\
(\mathrm{N}=977)\end{array}$ & $\begin{array}{c}\text { Depressed } \\
(\mathrm{N}=116)\end{array}$ \\
\hline Language, by Region of Origin & $239(24.5)$ & $\mathrm{N}$ (Conditional Proportion) \\
North American & $287(29.4)$ & $34(53.4)$ \\
Latin American & $75(7.7)$ & $4(3.5)$ \\
African & $315(32.2)$ & $14(12.1)$ \\
Asian & $1(0.1)$ & $2(1.7)$ \\
European & $52(5.3)$ & $0(0.0)$ \\
Middle Eastern & $8(0.8)$ & $0(0.0)$ \\
Other & & \\
\hline
\end{tabular}


Table 5. continued, Descriptives for the Study Population

\begin{tabular}{|c|c|c|}
\hline Characteristics & $\begin{array}{l}\text { Not Depressed } \\
\quad(\mathrm{N}=977)\end{array}$ & $\begin{array}{l}\text { Depressed } \\
(\mathrm{N}=116)\end{array}$ \\
\hline & N (Conditional Proportion) & N (Conditional Proportion) \\
\hline \multicolumn{3}{|l|}{ Race } \\
\hline White & $405(41.5)$ & $72(62.1)$ \\
\hline Black or African American & $223(22.8)$ & $25(21.6)$ \\
\hline Asian & 325 (33.3) & $15(12.9)$ \\
\hline American Indian or Alaska Native & $6(0.6)$ & $1(0.9)$ \\
\hline Other & $18(1.8)$ & $3(2.6)$ \\
\hline \multicolumn{3}{|l|}{ Ethnicity, by Region of Origin } \\
\hline American & $190(19.5)$ & $51(44.0)$ \\
\hline African & $127(13.0)$ & $8(6.9)$ \\
\hline Hispanic/Latino & $313(32.0)$ & $42(36.2)$ \\
\hline Asian & $337(34.5)$ & $15(12.9)$ \\
\hline European & $4(0.4)$ & $0(0.0)$ \\
\hline Other & $6(0.6)$ & $0(0.0)$ \\
\hline \multicolumn{3}{|l|}{ Ethnicity, by American Origin } \\
\hline American & $190(19.5)$ & $51(44.0)$ \\
\hline Non-American & $787(80.5)$ & $65(56.0)$ \\
\hline \multicolumn{3}{|l|}{ English Primary Language } \\
\hline No & $239(24.4)$ & $62(53.5)$ \\
\hline Yes & $738(75.6)$ & $54(46.5)$ \\
\hline \multicolumn{3}{|l|}{ Smoking } \\
\hline No & $885(90.6)$ & $96(82.8)$ \\
\hline Yes & $92(9.4)$ & $20(17.2)$ \\
\hline \multicolumn{3}{|l|}{ Alcohol Use } \\
\hline No & 947 (96.9) & $104(89.7)$ \\
\hline Yes & $23(2.4)$ & $12(10.3)$ \\
\hline Unknown & $7(0.7)$ & $0(0.0)$ \\
\hline
\end{tabular}


4.2.1 Assessment of the relationship between Birthweight and a Positive Screen for Prenatal Depression

To assess the relationship between birthweight and a positive screen for prenatal depression, the variables were defined as follows. Depression was measured using the EPDS screen. A score of 12 or greater on the EPDS screen was considered a Positive Screen for Prenatal Depression. A binary variable was created, dividing the study population into positive screen and negative screen groups. The raw infant birthweight in grams was converted into two separate variables. Raw birthweight was categorized into low birthweight (below 2500 grams) and normal birthweight (2500 grams and above) and is named birthweight-low/normal. The second birthweight variable categorized the raw birthweight into abnormal (less than 2500 grams or more than 4000 grams) and normal (between 2500 and 4000 grams) and is named birthweight-abnormal.

Ninety-one infants had low birthweight in the EPDS screened positive group, Figure 8. 26 infants were considered as having abnormal birthweight in the EPDS screened positive group, Figure 9. 
Figure 8: Birthweight divided into Low and Normal, by EPDS screen results

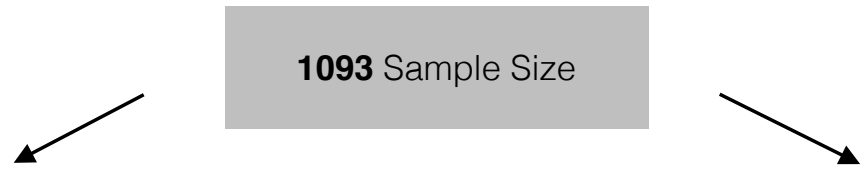

977 Screen Negative on

First Pregnancy EPDS

Screen

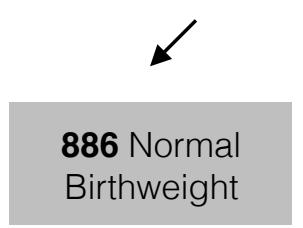

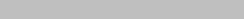

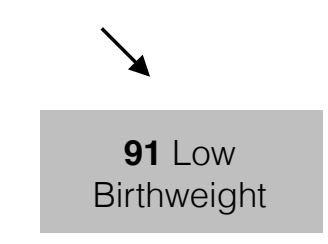

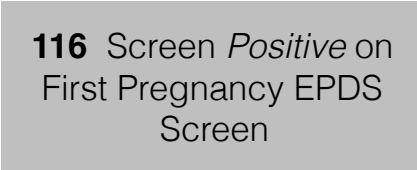

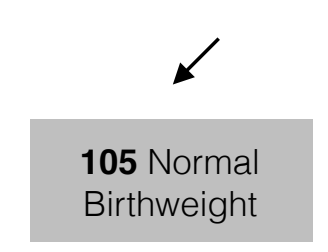

11 Low Birthweight

Figure 9: Birthweight divided into Abnormal and Normal, by EPDS screen results

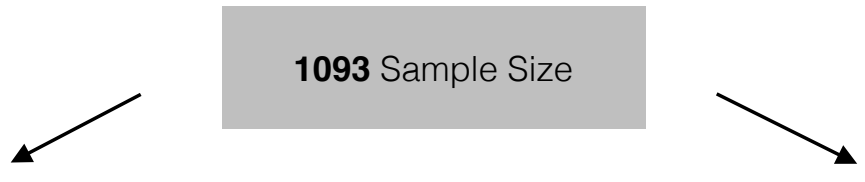

977 Screen Negative on

First Pregnancy EPDS

Screen

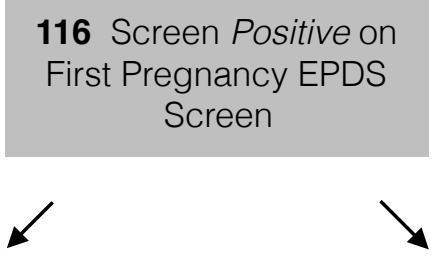

105 Normal Birthweight
11 Abnormal Birthweight
886 Normal Birthweight
91 Abnormal Birthweight

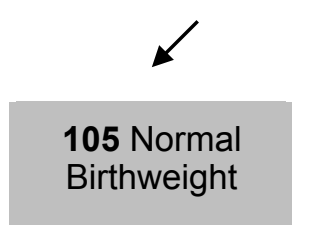

Crude analysis showed no increased risk of having an infant with low birthweight if one screened positive, OR $1.02(95 \% \mathrm{Cl} 0.53,1.97)$, Table 6 . There 
was also no increased risk of having an infant of abnormal weight if you screened positive with the EPDS screen, $1.02(95 \% \mathrm{Cl} 0.53,1.97)$, Table 6.

Univariate logistic regression confirmed what was seen in the crude analysis, that there is no statistically significant change of risk for an infant being born either with low birthweight (OR $1.02(95 \% \mathrm{Cl} 0.53,1.97))$ or abnormal birthweight (OR $1.02(95 \% \mathrm{Cl} 0.53,1.97))$ if a woman screens positive for prenatal depression with the EPDS screen, Table 6.

The need for strata specific regression was checked for using the Breslow-Day Test (35). As the Breslow-Day Test for Homogeneity of the Odds Ratios was greater than 0.05 for immigrant status $\left(X^{2}(1)=0.20,0.56\right)$, age $\left(X^{2}\right.$ $(39)=19.7,0.72)$, English as the primary language $\left(X^{2}(1)=0.00,0.99\right)$, pregnancy intention $\left(X^{2}(2)=2.90,0.23\right)$, and smoking status $\left(X^{2}(1)=0.00\right.$, 0.99), there is no heterogeneity between the strata specific OR and thus no interaction or effect modification, Table 7.

Further analysis of the logistic regression model, with Birthweight-Low/ Normal as the outcome, showed no association between any of the variables included and increased risk of having an infant with low birthweight: immigrant status $(\mathrm{OR}=0.41[95 \% \mathrm{Cl}=0.14,1.23])$, age $(\mathrm{OR}=1.01(95 \% \mathrm{Cl}=0.98,1.04))$, English as the primary language $(\mathrm{OR}=1.11[95 \% \mathrm{Cl}=0.37,3.20])$, pregnancy intention $(\mathrm{OR}=1.09[95 \% \mathrm{Cl}=0.91,1.29])$, and smoking status $(\mathrm{OR}=0.65[95 \%$ 
$\mathrm{Cl}=0.31,1.36])$. No statistical significance was seen in the main variable analyzed, EPDS screening result, $\mathrm{OR}=0.86(95 \% \mathrm{Cl}=0.49,1.66)$, Table 8 . Confounders of this analysis were as follows: age, immigrant status, English as the primary language, Table 8 .

Similar to the analysis of Birthweight-Low/Normal, the need for strata specific regression was checked for using the Breslow-Day Test for the Birthweight-Abnormal variable. As the Breslow-Day Test for Homogeneity of the Odds Ratios was greater than 0.05 for immigrant status $\left(X^{2}(1)=0.21,0.65\right)$, age $\left(X^{2}(24)=19.67,0.72\right)$, English as the primary language $\left(X^{2}(1)=0.00,0.99\right)$, pregnancy intention $\left(X^{2}(2)=0.90,0.23\right)$, and smoking status $\left(X^{2}(1)=0.00,0.99\right)$ there is no heterogeneity between the strata specific OR and thus no interaction or effect modification, Table 7.

Continued analysis of the logistic regression model, with BirthweightAbnormal variable as the outcome, showed no association between any of the variables included and increased risk of having an infant with abnormal birthweight: immigrant status $(\mathrm{OR}=0.41[95 \% \mathrm{Cl}=0.14,1.23])$, age $(\mathrm{OR}=1.01$ $(95 \% \mathrm{Cl}=0.98,1.04))$, English as the primary language $(\mathrm{OR}=1.11[95 \% \mathrm{Cl}=$ $0.39,3.20])$, pregnancy intention $(\mathrm{OR}=1.09[95 \% \mathrm{Cl}=0.91,1.29])$, smoking status $(\mathrm{OR}=0.65[95 \% \mathrm{Cl}=0.31,1.36])$, or the main variable of interest EPDS screening result, $\mathrm{OR}=0.85(95 \% \mathrm{Cl}=0.43,1.66)$, Table 8 . There were no confounders in this regression model. 
Table 6. Analysis: Birthweight and a Positive EPDS Screen

\begin{tabular}{lcc}
\hline \multicolumn{1}{c}{ Characteristics } & OR & 95\% Confidence Interval \\
\hline Crude Analysis & 1.02 & $0.53,1.97$ \\
Birthweight-Low/Normal & 1.02 & $0.53,1.97$ \\
Birthweight-Abnormal & & \\
& & \\
Univariate Analysis & 1.02 & $0.53,1.97$ \\
Birthweight-Low/Normal & 1.02 & $0.53,1.97$ \\
Birthweight-Abnormal & & \\
\hline
\end{tabular}

Table 7. Breslow Day Tests: Birthweight and a Positive EPDS Screen

\begin{tabular}{lcc}
\hline Characteristics & Chi-Square & P value \\
\hline Birthweight-Low/Normal & & 0.65 \\
Immigrant Status & 0.20 & 0.72 \\
Age & 19.70 & 0.99 \\
English, Primary Language & 0.00 & 0.23 \\
Pregnancy Intention & 2.90 & 0.99 \\
Smoking Status & 0.00 & \\
& & 0.65 \\
Birthweight-Abnormal & & 0.99 \\
Immigrant Status & 0.21 & 0.92 \\
Age & 0.00 & 0.99 \\
English, Primary Language & 19.66 & \\
Pregnancy Intention & 0.00 & \\
\hline
\end{tabular}


Table 8. Further Logistical Analysis: Birthweight and a Positive EPDS Screen

\begin{tabular}{|c|c|c|}
\hline Characteristics & OR & $95 \%$ Confidence Interval \\
\hline \multicolumn{3}{|l|}{ Birthweight-Low/Normal } \\
\hline $\begin{array}{l}\text { Screened Positive for Prenatal } \\
\text { Depression }\end{array}$ & 0.85 & $0.49,1.66$ \\
\hline Immigrant Status & $0.41^{\wedge}$ & $0.14,1.23^{\wedge}$ \\
\hline Age & $1.01^{\wedge}$ & $0.98,1.04^{\wedge}$ \\
\hline English, Primary Language & $1.11^{\wedge}$ & $0.37,3.20^{\wedge}$ \\
\hline Pregnancy Intention & 1.09 & $0.91,1.29$ \\
\hline Smoking Status & 0.65 & $0.31,1.36$ \\
\hline \multicolumn{3}{|l|}{ Birthweight-Abnormal } \\
\hline $\begin{array}{l}\text { Screened Positive for Prenatal } \\
\text { Depression }\end{array}$ & 0.85 & $0.43,1.66$ \\
\hline Immigrant Status & 0.41 & $0.14,1.23$ \\
\hline Age & 1.01 & $0.98,1.04$ \\
\hline English, Primary Language & 1.11 & $0.39,3.20$ \\
\hline Pregnancy Intention & 1.09 & $0.91,1.29$ \\
\hline Smoking Status & 0.65 & $0.31,1.36$ \\
\hline
\end{tabular}

\subsubsection{Assessment of the relationship between Gestational Age and a Positive Screen for Prenatal Depression}

In the assessment of Gestational Age and a Positive Screen for Prenatal Depression, the variables were defined as follows. The variable created with the results of the EPDS screening was described above. Gestational Age was used to create a new variable that considered preterm as 36 weeks below and term as 
37 weeks and above, called Gestation-PreTerm/Term. Twelve infants had a gestational age of equal to or less than 36 weeks in the EPDS screened positive group, Figure 10.

Figure 10: Gestational Age divided into Pre-Term and Full-Term, by EPDS screen results

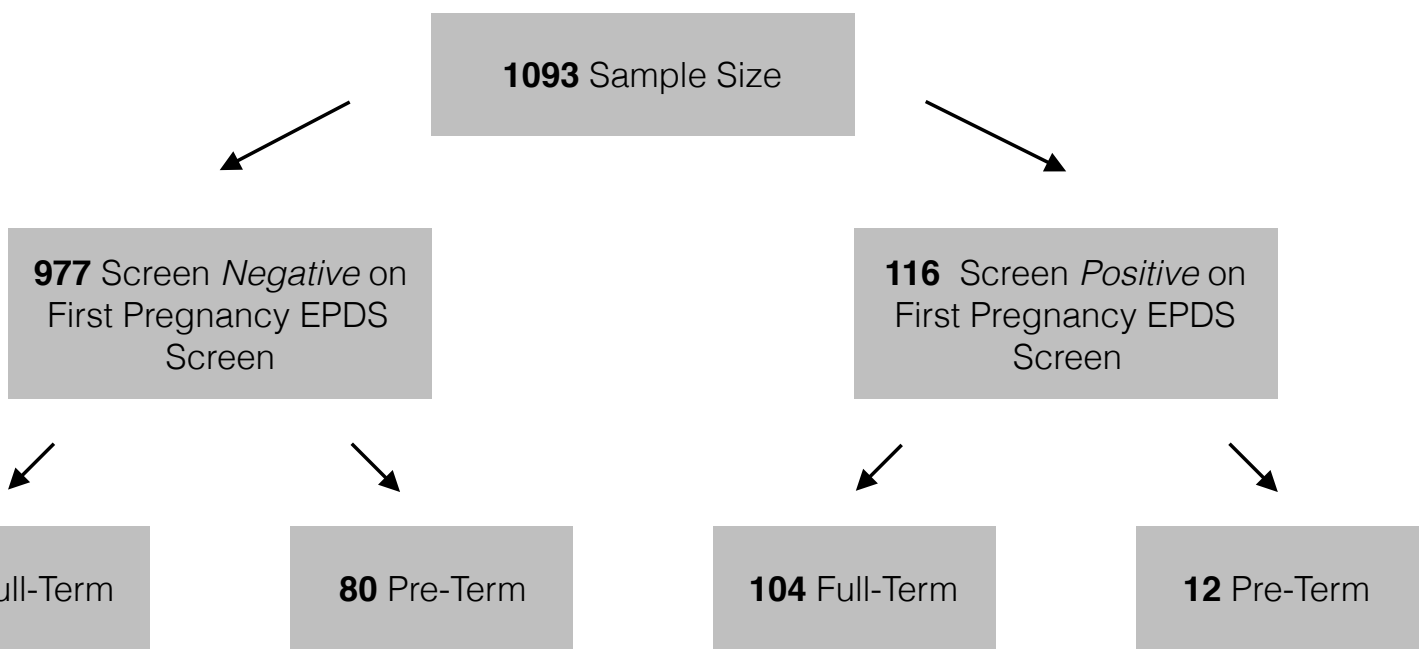

Crude analysis showed a slight increased risk of pre-term birth given a positive EPDS screen however the confidence interval shows that this is statistically insignificant, OR $1.29(95 \% \mathrm{Cl} 0.68,2.45)$, Table 9.

Univariate logistic regression showed that there is no statistically significant increase in risk for an infant being born pre-term (OR $1.29[95 \% \mathrm{Cl}$ $0.68,2.45])$ if a woman screens positive for prenatal depression with the EPDS screen, Table 9. 
Strata specific regression was assessed using the Breslow-Day Test. As the Breslow-Day Test for Homogeneity of the Odds Ratios was greater than 0.05 for immigrant status $\left(x^{2}(1)=2.34,0.13\right)$, age $\left(x^{2}(39)=16.29,0.87\right)$, English as the primary language $\left(X^{2}(1)=0.72,0.39\right)$, pregnancy intention $\left(X^{2}(2)=3.54\right.$, $0.17)$, and smoking status $\left(X^{2}(1)=2.34,0.13\right)$, there is no heterogeneity between the strata specific OR and thus no interaction or effect modification, Table 10.

Multivariate logistic analysis for Gestation-PreTerm/Term found that the main variable was confounded by two variables, immigrant status $(\mathrm{OR}=0.62$ $[95 \% \mathrm{Cl}=0.26,1.50])$ and english as a Primary language $(\mathrm{OR}=0.41[95 \% \mathrm{Cl}=$ $0.17,0.96])$, although only one was statistically significant, English as a primary language, Table 11. The other variables assessed did not confound the main variable of assessment, positive screen for prenatal depression: age $(O R=1.01$ $(95 \% \mathrm{Cl}=0.98,1.04))$, pregnancy intention $(\mathrm{OR}=1.12[95 \% \mathrm{Cl}=0.94,1.35])$, and Smoking Status $(\mathrm{OR}=0.72[95 \% \mathrm{Cl}=0.37,1.42])$ Table 11. A positive screen for prenatal depression was non-significant in the multivariate logistical model, $\mathrm{OR}=1.072(95 \% \mathrm{Cl}=0.615,1.869)$.

Table 9. Analysis: Gestation Age and a Positive EPDS Screen

\begin{tabular}{lcc}
\multicolumn{1}{c}{ Characteristics } & OR & 95\% Confidence Interval \\
\hline Crude Analysis & & \\
$\quad$ Gestation Age & 1.29 & $0.68,2.45$ \\
$\quad$ Pre-Term/Full-Term & & \\
Univariate Analysis & & $0.68,2.45$ \\
$\quad$ Gestation Age \\
Pre-Term/Full-Term
\end{tabular}


Table 10. Breslow Day Tests: Gestation Age and a Positive EPDS Screen

\begin{tabular}{lcc}
\multicolumn{1}{c}{ Characteristics } & Chi-Square & P value \\
\hline $\begin{array}{l}\text { Gestation Age } \\
\text { Pre-Term/Full-Term }\end{array}$ & & \\
Immigrant Status & 2.34 & 0.13 \\
Age & 16.29 & 0.87 \\
English, Primary Language & 0.73 & 0.39 \\
Pregnancy Intention & 3.54 & 0.17 \\
Smoking Status & 2.34 & 0.13 \\
\hline
\end{tabular}

Table 11. Further Logistical Analysis: Gestation Age and a Positive EPDS Screen

\begin{tabular}{lcc}
\hline \multicolumn{1}{c}{ Characteristics } & OR & $95 \%$ Confidence Interval \\
\hline $\begin{array}{l}\text { Gestation Age } \\
\text { Pre-Term/Full-Term }\end{array}$ & & \\
$\quad \begin{array}{l}\text { Screened Positive for Prenatal } \\
\text { Depression }\end{array}$ & 1.07 & $0.62,1.87$ \\
$\quad$ Immigrant Status & $0.62 \wedge$ & $0.26,1.50^{\wedge}$ \\
Age & 1.01 & $0.98,1,04$ \\
English, Primary Language & $0.41^{* \wedge}$ & $0.17,0.96 * \wedge$ \\
$\quad$ Pregnancy Intention & 1.12 & $0.94,1.35$ \\
$\quad$ Smoking Status & 0.72 & $0.37,1.42$ \\
\hline * indicates statistical significance, ${ }^{\wedge}$ indicates confounder of Screening Positive for Prenatal Depression
\end{tabular}

\subsubsection{Assessment of the Relationship between a Positive Screen for Prenatal Depression and Race and Ethnicity}

The relationship between screening positive for depression during pregnancy and race and ethnicity was looked at. To do this both the variables 
race and ethnicity were assessed independently. Language variables were also looked at as language can help explore ethnicity.

Race was found to have a significant association with screening positive for depression, $X^{2}(5)=27.08,<0.01$. Ethnicity by region of origin was also found to have a significant association with a positive EPDS screen, $X^{2}(5)=48.00$, $<0.01$. Also statistically significant were: immigrant status, $X^{2}(1)=31.44,<0.01$; English as a primary language, $X^{2}(1)=39.19,<0.01$; language by region of origin, $X^{2}(6)=51.97,<0.01$, Table 12 .

4.2.4 Assessment of the Relationship between a Positive Screen for Prenatal Depression and Other Variables

Significant association were found between the following variables and screening positive on the EPDS screen: pregnancy intention, $X^{2}(2)=15.92$, $<0.01$; Smoking, $X^{2}(1)=5.98,<0.01$; alcohol consumption, $X^{2}(2)=16.14,<0.01$, Table 12.

Non significant associations was seen in the variable number of previous pregnancies, $X^{2}(12)=15.14,0.23$, Table 12 . 
Table 12. Assessment of Variables and Screening Positive on EPDS

\begin{tabular}{|c|c|c|}
\hline Variable & Likelihood-Ratio Chi-Square & $\begin{array}{c}\text { Pr - Chi Square (Degrees of } \\
\text { Freedom) }\end{array}$ \\
\hline Race & $27.08^{*}$ & $<0.01(5)$ * \\
\hline Ethnicity by Region of Origin & 48.00 * & $<0.01(5)$ * \\
\hline Immigrant Status & 31.44 * & $<0.01(1)^{*}$ \\
\hline English as a Primary Language & 39.19 * & $<0.01(1)$ * \\
\hline Language by Region of Origin & 51.97 * & $<0.01(6)^{*}$ \\
\hline Pregnancy Intention & 15.92 * & $<0.01(2)$ * \\
\hline Smoking Status & 5.98 * & $0.01(1)$ * \\
\hline Alcohol Consumption & $16.14^{*}$ & $<0.01(2)$ * \\
\hline Previous Pregnancies & 15.14 & $0.23(12)$ \\
\hline
\end{tabular}

\subsubsection{Assessment of the Relationship between a Positive Screen for Prenatal Depression and Ethnicity by Global Region}

Further analysis was done on the variable ethnicity. The regions of origin were individually analyzed to see the associations between ethnic region of origin and screening positive for prenatal depression. Positive associations were found with American $\left(X^{2}(5)=22.7,<0.01\right)$ and Asian $\left(X^{2}(5)=18.9,<0.01\right)$ regions of origin. No associations were found with screening positive for prenatal depression and the following variables: African $\left(X^{2}(5)=3.7,0.59\right)$; Hispanic/ 
Latino $\left(X^{2}(5)=0.5,0.99\right)$; European $\left(X^{2}(5)=0.9,0.97\right)$; other $\left(X^{2}(5)=1.3\right.$, 0.93), Table 13.

Table 13, Ethnicity by Region of Origin

\begin{tabular}{lcc}
\hline \multicolumn{1}{c}{ Variable } & Likelihood-Ratio Chi-Square & Pr - Chi Square (5 Degrees of Freedom) \\
Ethnicity, by Region of Origin & $22.7^{*}$ & $<0.01^{*}$ \\
American & 3.7 & 0.59 \\
African & 0.5 & 0.99 \\
Hispanic/Latino & 18.9 * & $<0.01$ * \\
Asian & 0.9 & 0.97 \\
European & 1.3 & 0.93 \\
Other & & \\
\hline * indicates statistical significance &
\end{tabular}

4.2.6 Assessment of the Relationship between a Positive Screen for Prenatal Depression and Language by Global Region

Further analysis was done on the variable language. The regions of the participants language of origin were individually analyzed to see the associations between language region of origin and screening positive for prenatal depression. Positive associations were found with American $\left(X^{2}(6)=25.6\right.$, $<0.01)$ and Asian $\left(X^{2}(6)=11.7,<0.01\right)$ regions of origin. No associations were found with screening positive for prenatal depression and the following variables: African $\left(X^{2}(6)=3.1,0.80\right)$; Latin America $\left(X^{2}(6)=0.0,1.00\right)$; European $\left(X^{2}(6)\right.$ 
$=0.2,0.99)$; Middle Eastern $\left(X^{2}(6)=3.5,0.73\right)$;other $\left(X^{2}(6)=1.8,0.94\right)$, Table 14.

Table 14, Language by Region of Origin

\begin{tabular}{lcc}
\hline \multicolumn{1}{c}{ Variable } & Likelihood-Ratio Chi-Square & Pr - Chi Square (6 Degrees of Freedom) \\
\hline Language, by Region of Origin & $25.6^{*}$ & $<0.01^{*}$ \\
North American & 0.0 & 1.00 \\
Latin American & 3.1 & 0.80 \\
African & $17.7^{*}$ & $<0.01^{*}$ \\
Asian & 0.2 & 0.99 \\
European & 3.5 & 0.73 \\
Middle Eastern & 1.8 & 0.94 \\
Other & & \\
\hline * indicates statistical significance
\end{tabular}

4.2.7 Assessment of the Relationship between a Positive Screen for Prenatal Depression in Pregnancy and a Positive Screen for Prenatal Depression at Program Intake

Participants in the Healthy Start program are given the EPDS screen once they are accepted into the program. Some participants were pregnant upon intake while others become pregnant while they are a part of the program. Using the EPDS scores of those who were not pregnant at intake and then became pregnant we can compare the two scores to see if there was a difference. Of the 
305 women who were screened at intake and during pregnancy, 10 screened negative on intake and then screened positive for prenatal depression during pregnancy. 27 screened positive at intake and then screened negative for prenatal depression during pregnancy. 268 remained the same and 37 changes scored, Figure 11.

Figure 11: Flow chart showing change of EPDS score from program intake to pregnancy

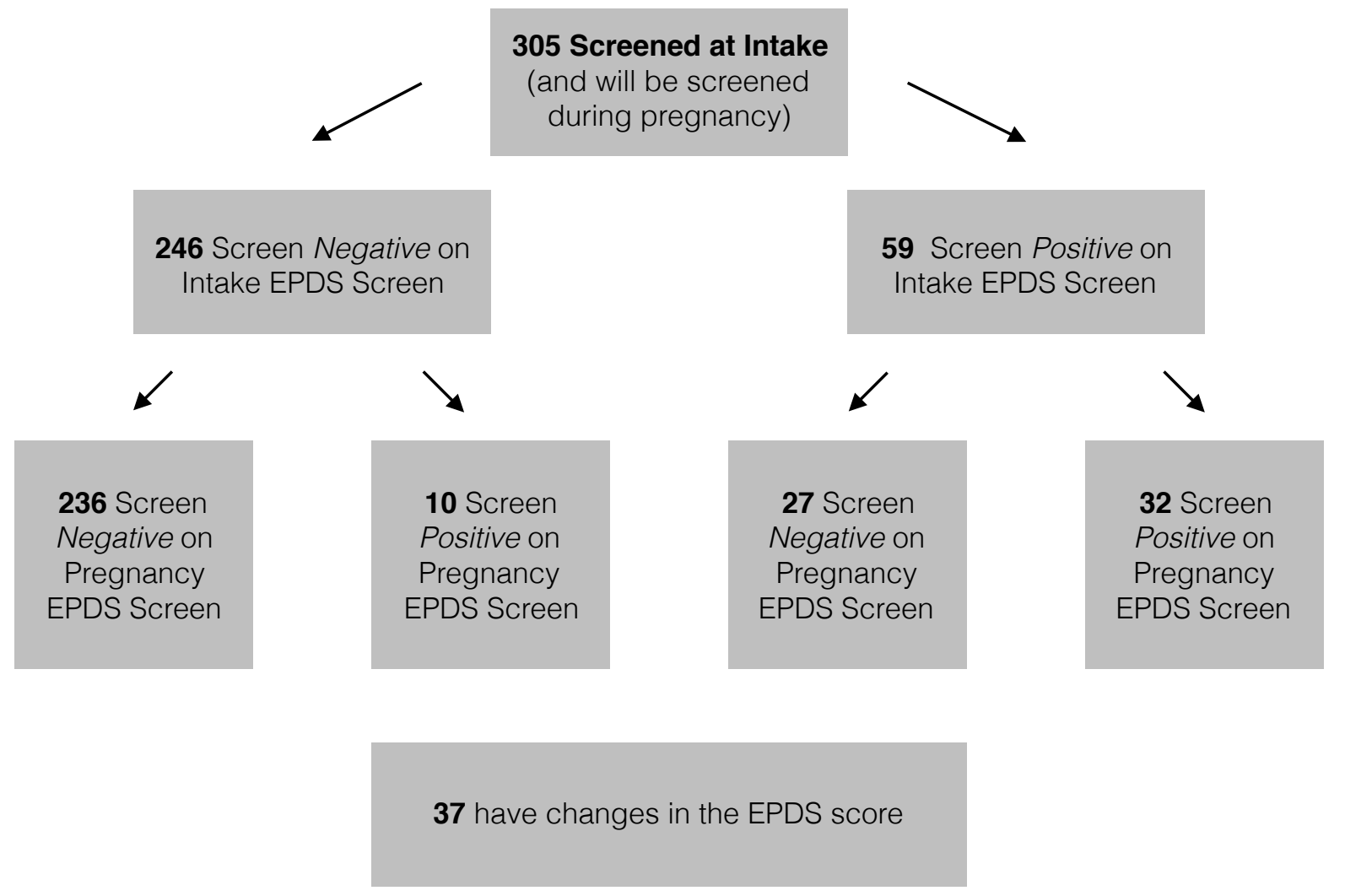




\section{DISCUSSION}

\subsection{Discussion of Results}

The study population was created from a Healthy Start Population in lowa. Although based in the midwest, this is a very racially and ethnically diverse population which allow for unique analysis to be done. One hundred and sixteen (116) people screened positive for depression, had birthweight listed, and had gestational length listed. Nine hundred seventy-seven (977) people screened negative on EPDS screening, had a listed birthweight, and had a listed gestational length. The total sample size was 1093, Figure 1.

In the analysis of depression and birthweight there was no significant association between screening positive for depression and birthweight.

Birthweight was was used to create variables so that all atypical birthweight could be analyzed. Neither of these created variables found a statistically significant association with having a positive screen for depression using EPDS screening, Table 6. None of the other variables assessed were found to have interaction or be effect modifiers in the logistic analysis of the birthweight variables and a positive depression screen. Confounders of Birthweight-Low/Normal wereEnglish as a primary language, immigrant status, and age. There were no confounders of the Birthweight-Abnormal model. The logistical analysis of Birthweight-Low/ 
Normal and Birthweight-Abnormal had no significant variables and were numerically similar, meaning there seems to be no large difference in different analyses of the birthweight variable.

Gestational Age was also used to assess the effects of screening positive for prenatal depression on birth outcomes. There was an increased risk seen in both the crude and univariate analyses, but both of these values are deemed to be non-significant due to their confidence intervals, Table 8 . As seen with birthweight, none of the other variables assessed interacted with or modified the logistic analysis. The confounders of the gestational age variable were immigrant status and English as the primary language. The only significant variable in the logistical analysis was English as the primary language.

When looking at the association between a positive depression screen and other variables there were statistically significant associations found. There was a statistically significant association between a positive EPDS screen and the following variables: race, ethnicity by region of origin, immigrant status, English as a primary language, and language by region of origin. These potential cultural associations could lead to further studies that assess ethnicities and race and prenatal depression and look at the social factors that may be involved or contribute to prenatal depressions. 
Smoking status and alcohol were both found to be statistically significantly associated with screening positive prenatal depression, which makes plausible sense as they are known to have associations with depression. Pregnancy intention was found to be associated with a positive EPDS screen. Pregnancy intention could play a large role in the attitudes seen throughout pregnancy. Previous pregnancies were found to be not associated with a positive prenatal depression screen.

Further analysis of the ethnicity by region of origin saw that there was a significant association between being from America or Asia and screening positive on the EPDS. Analysis of language by region of origin also showed a positive association between a language origin being American or Asian and scoring positive on the EPDS.

The mix of significant and non-significant results are most likely due to this study being underpowered. That being said, there are still some interesting trends in this study, especially in conjunction with how EPDS is administered. When EPDS is offered in this population, only English, Spanish, and Arabic are offered in written form. If a person is illiterate or does not read and write any of these languages, then the person will be given the questions orally by a trained interpreter. This leaves room for interpreter bias. If the questions are not asked in the same manner every time, there could be lack of consistency in EPDS results. Also, if the questions are asked with a literal interpretation, this could cause a 
lack of understanding in the questions and lead to non accurate results. Another potential problem is with this being a Healthy start population. The participants may feel like they need to answer one way or another to be able to remain a part of the program, and thus influence results.

This is an ethnically diverse population and with that comes a host of cultural differences, norms, and stigmas within this population, any of which could also influence screening results. As ethnicity and language, along with other variables, show an association with screening positive on EPDS, this shows the need for further analysis into the cultural norms and stigmas of this population and validity of EPDS within the Healthy Start population. 


\section{CONCLUSION}

\subsection{Conclusion}

In this study population there is no increased risk of atypical birthweight given a positive EPDS score. However there is an association of a positive EPDS score and the following variables: race, ethnicity by region of origin, immigrant status, English as a primary language, and language by region of origin, pregnancy intention, smoking status, and alcohol consumption. This could be due to a true association, but it could also be due to how the EPDS screen is given in this population, either in written form or orally depending on the language knowledge and literacy of the participant.

Nevertheless, interesting information can be pulled from the association between a positive EPDS score and variables based on race, ethnicity, and language. Using a variety of ways to explain these variables (region of origin, english as a primary language, immigrant status, etc.) helped to explore the complexity in analyzing ethnicity as a variable as they show that ethnicity plays a role in prenatal depression in more than one way. Ethnicity and language are intertwined. 
Further analysis on these variables will need to be done with a much larger sample group to determine true associations, and further analysis should include ethnicity and other cultural markers to help determine the effects of ethnicity and its cultural context on prenatal depression.

\subsection{Limitations}

As previously mentioned one of the limitations of this study is that is is under powered. For any meaningful conclusions to be made, the study will need to be repeated with a much larger sample size to missing data will need to be addressed. Another limitation of this study is in how EPDS screening is done. Because it is either an oral or written interview, depending on the language use and literacy of the participant, with a case worker or interpreter, there is significant room for bias. The multi-cultural population could also have cultural norms influence screening results. These may lead to false positives and false negatives in the screening results. Further studies should have two measures of screening for prenatal depression so that validity can be obtained. 


\section{REFERENCES}

1. Grote NK, Bridge JA, Gavin AR, et al. A meta-analysis of depression during pregnancy and the risk of preterm birth, low birth weight, and intrauterine growth restriction. Archives of general psychiatry 2010;67(10):1012-24.

2. Grigoriadis S, VonderPorten EH, Mamisashvili L, et al. The impact of maternal depression during pregnancy on perinatal outcomes: a systematic review and metaanalysis. The Journal of clinical psychiatry 2013;74(4):e321-41.

3. Husain N, Munshi T, Jafri F, et al. Antenatal Depression is Not Associated with Low-Birth Weight: A Study from Urban Pakistan. Frontiers in psychiatry 2014;5:175.

4. Varela P, Spyropoulou AC, Kalogerakis Z, et al. Limited Depressive and Anxiety Symptoms Late in Pregnancy Are Not Related to Neonatal Outcomes. Nursing and midwifery studies 2015;4(3):e29308.

5. Andersson L, Sundstrom-Poromaa I, Wulff M, et al. Neonatal outcome following maternal antenatal depression and anxiety: a population-based study. American journal of epidemiology 2004;159(9):872-81.

6. Diego MA, Field T, Hernandez-Reif M, et al. Prenatal depression restricts fetal growth. Early Human Development 2009;85(1):65-70.

7. Saeed A, Raana T, Saeed AM, et al. Effect of antenatal depression on maternal dietary intake and neonatal outcome: a prospective cohort. Nutrition journal 2016;15(1): 64. 
8. Field T, Diego M, Hernandez-Reif M, et al. Depressed pregnant black women have a greater incidence of prematurity and low birthweight outcomes. Infant behavior \& development 2009;32(1):10-6.

9. Niemi M, Falkenberg T, Petzold M, et al. Symptoms of antenatal common mental disorders, preterm birth and low birthweight: a prospective cohort study in a semi-rural district of Vietnam. Tropical Medicine \& International Health 2013;18(6):687-95.

10. Gentile S. Untreated depression during pregnancy: Short- and long-term effects in offspring. A systematic review. Neuroscience 2015.

11. Yedid Sion M, Harlev A, Weintraub AY, et al. Is antenatal depression associated with adverse obstetric and perinatal outcomes? The journal of maternal-fetal \& neonatal medicine : the official journal of the European Association of Perinatal Medicine, the Federation of Asia and Oceania Perinatal Societies, the International Society of Perinatal Obstet 2016;29(6):863-7.

12. APA. Depressive Disorders. 5th ed. Washington DC; 2013.

13. Hasler G. PATHOPHYSIOLOGY OF DEPRESSION: DO WE HAVE ANY SOLID EVIDENCE. World Psychiatry 2010;9(3):155-61.

14. CDC. Depression in the U.S. Household Population, 2009-2012. cdc.gov: CDC; 2016. (http://www.cdc.gov/nchs/products/databriefs/db172.htm). (Accessed November 16, 2016 2016).

15. Marcus SM. Depression during pregnancy: rates, risks and consequences-Motherisk Update 2008. The Canadian journal of clinical pharmacology = Journal canadien de pharmacologie clinique 2009;16(1):e15-22.

16. Leigh B, Milgrom J. Risk factors for antenatal depression, postnatal depression and parenting stress. BMC psychiatry 2008;8:24. 
17. Lefkovics E, Baji I, Rigo J. Impact of maternal depression on pregnancies and on early attachment. Infant mental health journal 2014;35(4):354-65.

18. CDC. Births: Final Data for 2014. National Vital Statistics Reports 2015;64(12).

19. Accortt EE, Cheadle AC, Dunkel Schetter C. Prenatal depression and adverse birth outcomes: an updated systematic review. Matern Child Health J 2015;19(6): 1306-37.

20. Shakeel N, Eberhard-Gran M, Sletner L, et al. A prospective cohort study of depression in pregnancy, prevalence and risk factors in a multi-ethnic population. BMC Pregnancy Childbirth 2015;15:5.

21. Gavin AR, Melville JL, Rue T, et al. Racial differences in the prevalence of antenatal depression. General hospital psychiatry 2011;33(2):87-93.

22. Rich-Edwards JW, Kleinman K, Abrams A, et al. Sociodemographic predictors of antenatal and postpartum depressive symptoms among women in a medical group practice. Journal of epidemiology and community health 2006;60(3):221-7.

23. Mukherjee S, Trepka MJ, Pierre-Victor D, et al. Racial/Ethnic Disparities in Antenatal Depression in the United States: A Systematic Review. Matern Child Health J 2016;20(9):1780-97.

24. Collins $\mathrm{CH}$, Zimmerman C, Howard LM. Refugee, asylum seeker, immigrant women and postnatal depression: rates and risk factors. Archives of women's mental health 2011;14(1):3-11.

25. Nithianandan N, Gibson-Helm M, McBride J, et al. Factors affecting implementation of perinatal mental health screening in women of refugee background. Implementation science : IS 2016;11(1):150.

26. DHS I. History of the Bureau. IOWA.GOV; 2017. (http://dhs.iowa.gov/refugeeservices/history). (Accessed 2017). 
27. Kozinszky Z, Dudas RB. Validation studies of the Edinburgh Postnatal Depression Scale for the antenatal period. Journal of affective disorders 2015;176:95-105.

28. Shrestha SD, Pradhan R, Tran TD, et al. Reliability and validity of the Edinburgh Postnatal Depression Scale (EPDS) for detecting perinatal common mental disorders (PCMDs) among women in low-and lower-middle-income countries: a systematic review. BMC Pregnancy and Childbirth 2016;16:72.

29. Tsai AC, Scott JA, Hung KJ, et al. Reliability and validity of instruments for assessing perinatal depression in African settings: systematic review and meta-analysis. PloS one 2013;8(12):e82521.

30. Smith MV, Shao L, Howell H, et al. Perinatal Depression and Birth Outcomes in a Healthy Start Project. Maternal and Child Health Journal 2011;15(3):401-9.

31. Yonkers KA, Smith MV, Lin H, et al. Depression screening of perinatal women: an evaluation of the healthy start depression initiative. Psychiatric services (Washington, DC) 2009;60(3):322-8.

32. Brand A, Walker DK, Hargreaves M, et al. Intermediate outcomes, strategies, and challenges of eight healthy start projects. Matern Child Health J 2010;14(5):654-65.

33. Segre LS, O'Hara MW, Brock RL, et al. Depression Screening of Perinatal Women by the Des Moines Healthy Start Project: Program Description and Evaluation. Psychiatric Services 2012;63(3):250-5.

34. Venkatesh KK, Nadel H, Blewett D, et al. Implementation of universal screening for depression during pregnancy: feasibility and impact on obstetric care. American Journal of Obstetrics and Gynecology 2016;215(4):517.e1-.e8.

35. Armitage P, Colton T. Encyclopedia of biostatistics. 2nd ed. Chichester, West Sussex, England ; Hoboken, NJ: John Wiley; 2005. 


\section{CURRICULUM VITA}

NAME: $\quad$ Evangeline Jane Pierce

ADDRESS: 1500 River Shore Drive Apt 312, Louisville, KY 40206

270-579-3055

ejpier01@louisville.edu

DOB: $\quad$ Miami, Florida - December 22, 1987

EDUCATION

\& TRAINING: $\quad$ B.S. Chemistry

Western Kentucky University

2007-2010

AWARDS: Scholar of Ogden College, December 2010 at Western Kentucky University

Presidents Scholar January 2007-December 2010 at Western Kentucky University

CURRENT POSITIONS: Director of Content and Curriculum, Global Missions Health Conference

RESEARCH EXPERIENCE: $\quad$ Community Based Research - June 2016

Research Assistant - June 2013 to August 2013 